\title{
Micro/Nanostructured Lignonanocellulose Obtained from Steam-Exploded Sugarcane Bagasse
}

\author{
André Mazega Fontes \\ Universidade Federal do Paraná: Universidade Federal do Parana \\ Cleverton L. Pirich \\ Universidade Federal do Paraná: Universidade Federal do Parana \\ Gustavo Ryo Oliveira de Andrade Tanobe \\ Federal University of Parana: Universidade Federal do Parana \\ Quim Tarrés \\ University of Girona: Universitat de Girona \\ Marc Delgado-Aguilar \\ University of Girona: Universitat de Girona \\ Luiz Pereira Ramos ( $\nabla$ Iramos@quimica.ufpr.br) \\ Universidade Federal do Parana
}

\section{Research Article}

Keywords: sugarcane bagasse, steam explosion, delignification, enzyme-assisted high-pressure homogenization, lignonanocellulose.

Posted Date: June 2nd, 2021

DOl: https://doi.org/10.21203/rs.3.rs-552986/v1

License: (c) (1) This work is licensed under a Creative Commons Attribution 4.0 International License.

Read Full License 


\section{Micro/nanostructured lignonanocellulose obtained 2 from steam-exploded sugarcane bagasse}

3

4

5

6
André M. Fontes ${ }^{a}$, Cleverton L. Pirich ${ }^{a}$, Gustavo R. O. A. Tanobe ${ }^{a}$, Quim Tarrés ${ }^{b}$, Marc Delgado-Aguilarb $^{\mathrm{b}}$ Luiz P. Ramos ${ }^{\mathrm{a}}$

${ }^{a}$ Chemistry Department, Federal University of Paraná (UFPR), 81531-980 Curitiba, PR, Brazil ${ }^{b}$ LEPAMAP-PRODIS Research Group, University of Girona. Maria Aurèlia Capmany, 61 17003 Girona (Spain)

* Corresponding authors: Luiz Pereira Ramos (luiz.ramos@ufpr.br); Phone: +55 41 3361-3175; Fax: +55 413361-3186.

\section{Abstract}

This work demonstrates the isolation of lignocellulose micro-nanofibrils, nanocrystals and nanospheres from steam-exploded sugarcane bagasse (SEB). First, steam-explosion was carried out in sugarcane bagasse at $195{ }^{\circ} \mathrm{C}$ for 7.5 and 15 min (SEB-7.5 and SEB-15). Untreated sugarcane bagasse was also pretreated by mechanical refining (MRB) in a PFI mill for comparison. Then, SEB and MRB fibers were submitted to alkaline delignification, hypochlorite bleaching for 60 or $180 \mathrm{~min}$ (HB60 and HB180), enzymatic hydrolysis (endoglucanase), and high-pressure homogenization. The resulting materials were characterized regarding chemical composition by high-performance liquid chromatography, width and morphology by transmission electron microscopy, crystallinity by X-ray powder diffraction and aspect ratio (length/diameter) by rheology. Levels of glucans (mostly cellulose), hemicelluloses and lignin were: $53.8 \%, 19.7 \%$ and $11.6 \%$ in MRB-HB180; 87.8\%, $<0.1 \%$ and $7.2 \%$ in SEB-7.5-HB60; 84.3\%, $<0.1 \%$ and $4.8 \%$ in SEB-7.5-HB180, 85.9\%, $<0.1 \%$ and $8.4 \%$ in SE-15-HB60; and $82.2 \%,<0.1 \%$ and $5 \%$ in SE-15-HB180, respectively. Aspect ratios and crystallinity indexes were similar among all groups ( 100 and $\sim 73 \%$, respectively), except for SE-15-HB180 ( 78.5 and 77\%, respectively). MRB-HB180 and SE-15 (HB60 and HB180) had the lowest fiber widths $(<20 \mathrm{~nm})$ with the presence of nanocrystals in SE-15-HB180, while in the SE-7.5 (HB60 and HB180), fiber widths were greater than $50 \mathrm{~nm}$ with the presence of lignin nanospheres in SE-7.5-HB60. Hence, lignocellulose nanomaterials with aspect ratios ranging from micro/nanofibers to nanocrystals were isolated from SEB using a cost-effective production process.

Keywords: sugarcane bagasse, steam explosion, delignification, enzyme-assisted highpressure homogenization, lignonanocellulose. 


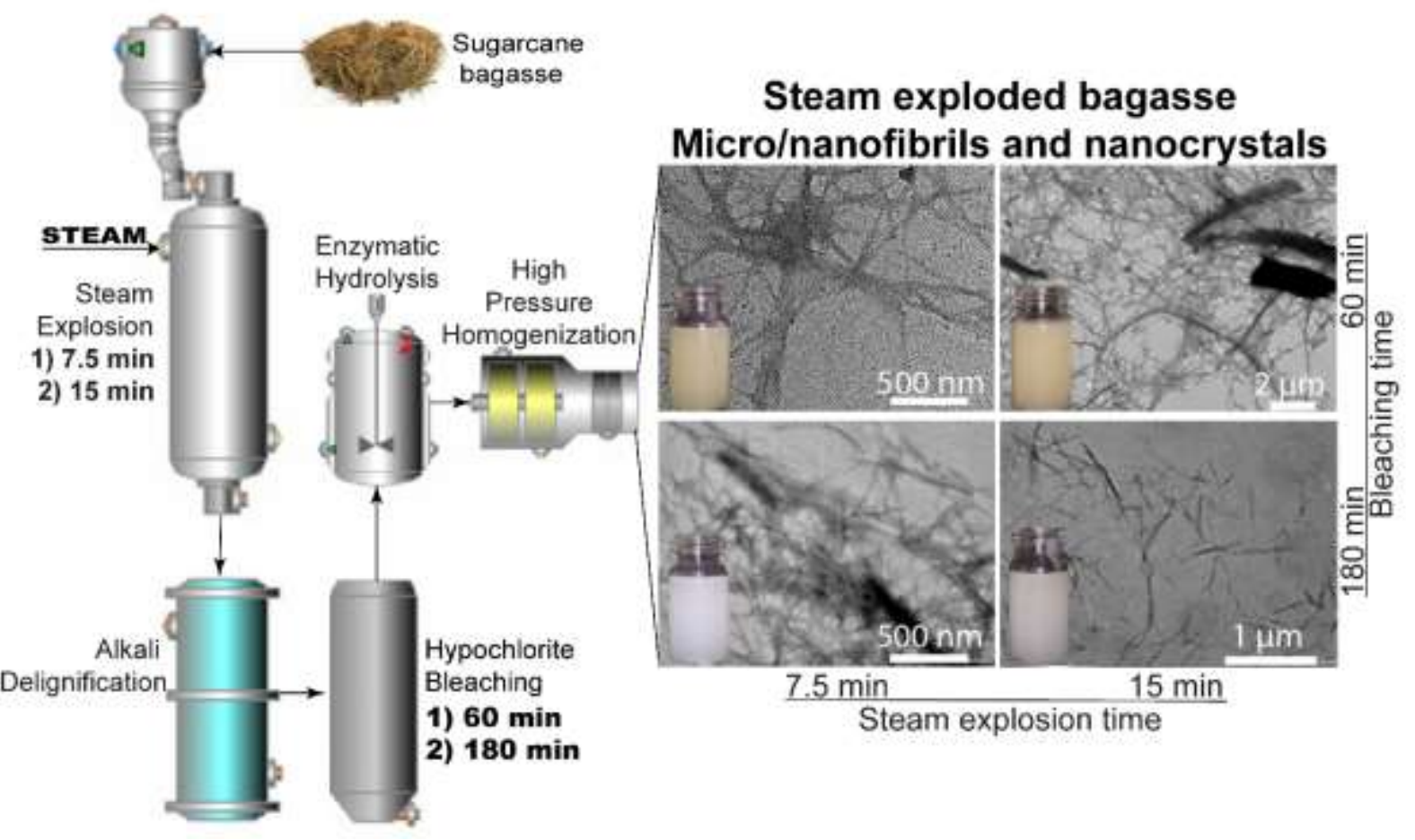

\section{Introduction}

Worldwide agro-industrial activities generate substantial amounts of residual waste streams every year. Notwithstanding the fact that these residues are often originated from nontoxic resources, their improper disposal may cause environmental pollution and a severe impact on human health. One common industrial destination that avoids solid waste disposal is its incineration to produce bioelectricity or combined heat and steam, which must be carried out under strict control to reduce greenhouse gas emissions as much as possible. In general, energy savings in the range of US $\$ 200$ to 400 can be achieved for every 1 ton of burnt wastes (dry basis) (Mathur and Srivastava 2019). By contrast, cellulosic crop residues can be utilized for the isolation of nanocelluloses, whose selling price is in the range of US\$2,000-20,000 ton${ }^{1}$ (Assis et al. 2017; Assis et al. 2018). Nanocelluloses, some of which already industrially available, are of special interest due to their high added-value and broad spectrum of applications. Although nanocellulose biocompatibility and biodegradability are key for applications in sustainable products, technological developments are still lacking to accommodate a cost-effective production process, adapted to local resources and to the type of feedstock available as raw material. Further, most of the commercially available nanocelluloses come from bleached chemical pulps, which leads to a low yield of the whole operation. 
Cellulose nanofibers, defined as nano-objects with width in nanoscale (3-30 nm), are divided into two types: cellulose nanofibers (CNF) containing both crystalline and amorphous regions with aspect ratio (length/width) usually greater than 50, and cellulose nanocrystals (CNC) containing predominantly crystalline and paracrystalline regions with aspect ratio usually lower than 50 and greater than 5, not exhibiting longitudinal splits, inter-particle entanglement, or network-like structures (Kumagai et al. 2019; Mariano et al. 2014). Mainly due to their excellent physical-chemical (e.g., non-toxic, biocompatible, anisotropic, and high in surface area) and mechanical properties, nanocellulosic materials have gained industrial attention for a wide range of applications, such as in the biomedical, food, cosmetics, construction, automotive and aerospace industries (Hiloidhari et al. 2020; Huang et al. 2019; Wu et al. 2019).

Sulfated-CNC and oxidated-CNF (e.g., Celluforce ${ }^{\circledR}$ and Nippon ${ }^{\circledR}$, respectively) are examples of commercially available nanocellulosic materials. Sulfated-CNC are obtained by hydrolysis of bleached cellulose using 50 to $60 \mathrm{wt} \%$ dilute sulfuric acid at 50 to $60{ }^{\circ} \mathrm{C}$. After neutralization and several washing steps, the resultant CNC possesses high colloidal stability due to its anionic surface $\left(\mathrm{R}-\mathrm{OSO}_{3}{ }^{-}\right.$with zeta potential of -30 to $-60 \mathrm{mV}$ at pH 7.0) (Pirich et al. 2019). Hence, sulfated CNC can be easily dispersed in water even after spray-drying due to electrostatic repulsion. On the other hand, these materials have a relatively low thermostability, from $\sim 300^{\circ} \mathrm{C}$ for bleached cellulose or non-functionalized CNC to $\sim 160{ }^{\circ} \mathrm{C}$ for sulfated CNC (Nan et al. 2017), which limits application in processes such as thermal extrusion (e.g., blends with polyamides at $270^{\circ} \mathrm{C}$ ) (Sucharitpong et al. 2020). Oxidated-CNF are obtained by a preoxidation step of bleached cellulose using (2,2,6,6-tetramethylpiperidn-1-yl)oxyl (TEMPO) as catalyst in alkaline medium $(\mathrm{pH} 10)$. After neutralization, the C6-carboxylated fiber surface allows defibrillation to the nanoscale dimensions (diameters $<100 \mathrm{~nm}$ ) by mechanical treatment (e.g., microgrinding and high-pressure homogenization) with considerable energy savings, from $>200 \mathrm{~kW} \mathrm{~h}^{-1} \mathrm{~kg}^{-1}$ to $\leq 1 \mathrm{~kW} \mathrm{~h}^{-1} \mathrm{~kg}^{-1}$ (Zhou et al. 2018).

The main problems regarding both methodologies are the use of environmentally hazardous chemicals, the requirement of high-cost corrosion-resistant equipment, and the need for remediation of side reaction products such as sulfuric acid. Side products such as fermentable sugars could be further used for biofuels production and this may represent an important contribution to the process economics (Arantes and Saddler 2011; Chinga-Carrasco et al. 2019; Xie et al. 2018).

An interesting alternative for $\mathrm{CN}$ production is the auto-hydrolysis of lignocellulosic materials by steam explosion (SE), a technique that is well-established at industrial scale for cellulosic ethanol production. SE consists in pretreating biomass with saturated steam at high pressures and high temperatures by short residence times, followed by the abrupt 
decompression of the reaction vessel causing the explosion effect (Bhatia et al. 2019). During this process, the high-pressure steam penetrates the biomass structure, releasing its latent heat of vaporization. With this, acetic acid is released from the acetyl groups of hemicelluloses, promoting their partial hydrolysis into oligomers and monomers, depending on pretreatment severity. Lignin is coalesced and redistributed in small particles, while cellulose is affected to a much lesser extent, being normally recovered in high yields (Bhatia et al. 2019). With this, biomass recalcitrance is partially compromised, and pretreated materials are made more accessible to physical, chemical and biological conversion. Also, the explosion effect imposes a significant physical stress to the already softened lignocellulosic material, helping the breakdown of fiber-to-fiber bonding, and leading to a significant increase in both substrate porosity and surface area. The final product is composed of a thick fiber slurry that generates water-soluble and water-insoluble fractions by filtration. The first is mainly composed of hemicellulose sugars (C5 stream) and dehydration by-products, while the latter contains lignified cellulosic fibers that could be used for nanocellulose production after delignification.

The minimum selling price of commercial oxidated-CNF ranges from USD 1,893 to 2,440 ton $^{-1}$ (Assis et al. (2018), while that of sulfated-CNC ranges from USD 5,900 to 7200 ton $^{-}$ ${ }^{1}$ (Assis et al. (2017). On the other hand, Metgen ${ }^{\circledR}$ recently estimated the cost of CNC production in $€ 500$ to 800 ton $^{-1}$ when produced as a biorefinery side streams (Metgen 2021). As most of these processes are based on bleached kraft pulps, the development of nanocellulose isolation from agricultural residues could represent a huge reduction of the final product cost. Furthermore, $\mathrm{CN}$ extracted from pretreated lignocellulosic materials may retain moderate lignin contents, rendering nanomaterials with interesting physical and chemical properties. Nanocelluloses containing lignin or lignified nanocelluloses (LNC) are considerably less hydrophilic than lignin-free nanocelluloses, and this may improve their interaction with hydrophobic materials as well as their drying, transport and storage performances (Deepa et al. 2019; Gu et al. 2019; Silva et al. 2019).

Due to the strong association that exists in lignin-carbohydrate complexes, high pretreatment severities (e.g., high temperatures and residence times, use of exogenous acid catalysts, and application of high shearing strengths in mechanical treatments) and delignification (e.g., alkaline washing, solvent extraction, and oxidative bleaching) are needed to obtain nanomaterials with desirable physical and chemical properties (Kumar et al. 2014; Zhou et al. 2018). The presence of lignin impairs the isolation of nanoscale particles because it acts as a lubricant that reduces shearing during mechanical refining. However, Rojo et al. (2015) demonstrated that partial delignification, from 30-40 wt\% to 7-11 wt\% lignin contents, was already enough to improve the micro-grinding performance to produce lignocellulose nanofibers (LCNF). The presence of relatively low lignin contents in biomass, although 
130 requiring higher mechanical energy for grinding, produced nanofibers with narrower diameter 131 distributions. Another detrimental effect of lignin is enzyme adsorption when endoglucanases 132 are used to facilitate mechanical refining by weakening fiber strength and fiber-to-fiber bonding 133 (Han et al. 2021; Lu et al. 2018). In addition, Pereira and Arantes (2020) carried out the 134 enzymatic hydrolysis of bleached steam-exploded sugarcane bagasse (SEB) to obtain a 135 soluble fraction with high sugar concentration (> $120 \mathrm{~g} \mathrm{~L}^{-1}$ glucose) and an insoluble fraction with CNCs with $20 \mathrm{~nm}$ in diameter.

In this work, the extraction of LNC from partially bleached SEB was evaluated. The variables explored in the reaction were steam explosion residence times of 7.5 and $15 \mathrm{~min}$ at $195^{\circ} \mathrm{C}$ and sodium hypochlorite $(\mathrm{NaOCl})$ bleaching times of 60 and $180 \mathrm{~min}$. All resulting materials were pre-hydrolyzed with endoglucanases followed by mechanical treatment with high-pressure homogenization. LNC with different aspect ratios were obtained with characteristics of lignocellulose nanocrystals (LCNC) and LCNF by varying steam explosion and bleaching times. These results demonstrated that lignin-containing cellulosic nanomaterials with interesting and tailored properties and characteristics could be successfully obtained from steam-exploded sugarcane bagasse.

\section{Materials and Methods}

\section{Materials}

Sugarcane bagasse was donated by Raízen ${ }^{\circledR}$ (Piracicaba, SP). Other reagents were acquired in analytical grade from Sigma-Aldrich ${ }^{\circledR}$. Standards (glucose, xylose, arabinose, acetic acid, furfural and 5-(hydroxymethyl)furfural), solvents, and reagents for chromatographic and spectrometric analyses were acquired at the specification required by the corresponding analytical procedures. The endoglucanase (Novozymes 476) used for hydrolysis was supplied by Novozymes ${ }^{\circledR}$ (Bagsværd, Denmark). A simplified diagram of the experimental approach is illustrated in Figure 1. 
158 Figure 1. Flow diagram of the global reactions to obtain nanofibers of cellulose

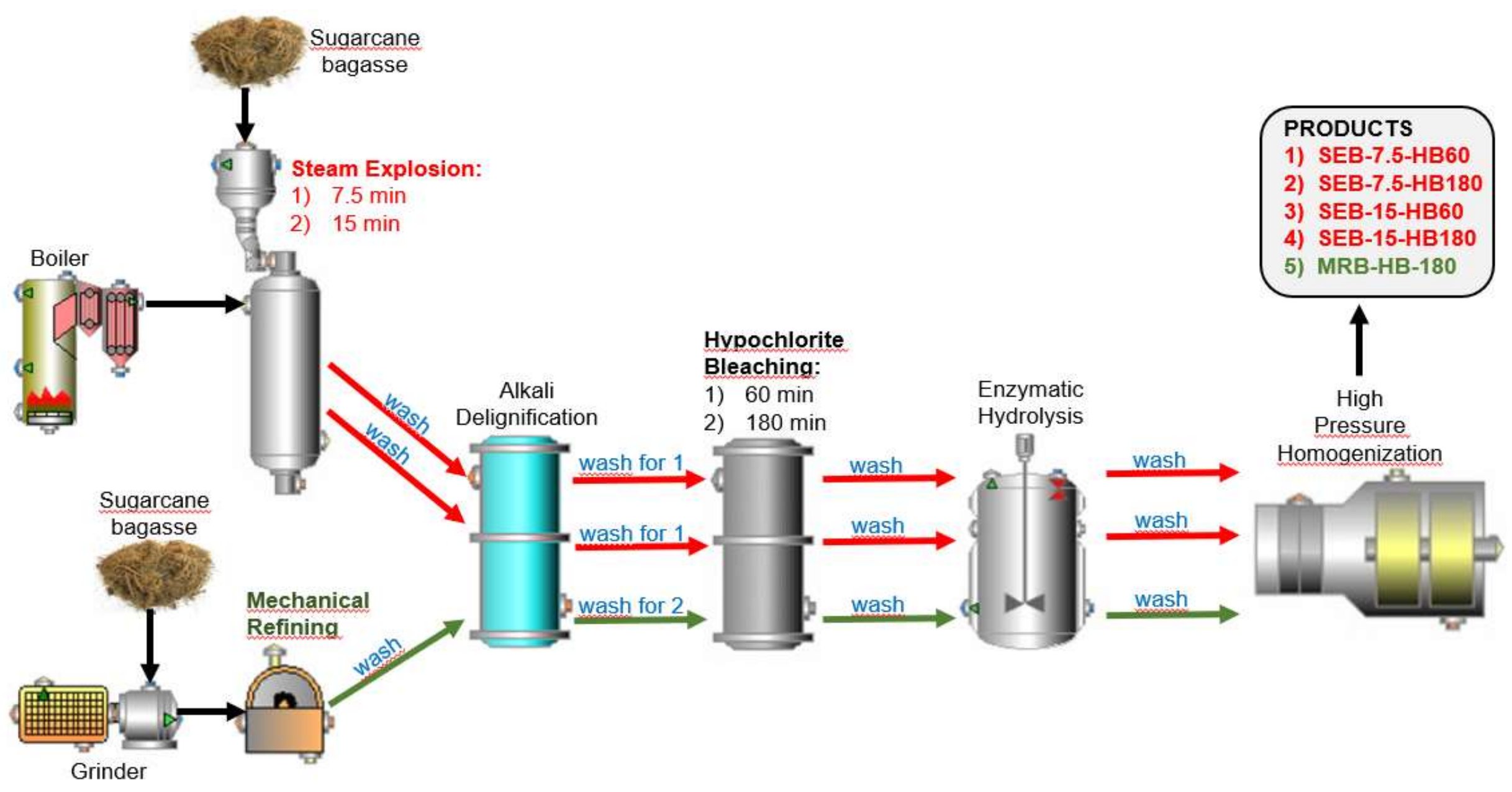




\section{Steam explosion by auto-hydrolysis}

Sugarcane bagasse (50 wt.\% moisture content) was pretreated by steam explosion in a 10-L stainless steel reactor connected to a high-pressure steam boiler and equipped with sensors to monitor temperature and reaction time. The reaction conditions were based on the preliminary studies of Pitarelo et al. (2016), using $195^{\circ} \mathrm{C}$ for reaction times of 7.5 and $15 \mathrm{~min}$. After this, the pretreated material was released from the pressure vessel into a stainless-steel cyclone where it was collected from with a moisture content of $75-80 \mathrm{wt} . \%$. Then, the pretreatment slurry was centrifuged to separate the pretreated fibers from the water-soluble acid hydrolysate (C5 stream). The solid fraction was washed with water at $10 \mathrm{wt} \%$ waterinsoluble solids (WIS) for $60 \mathrm{~min}$ under mechanical stirring (150 rpm) at room temperature $\left(\sim 25^{\circ} \mathrm{C}\right)$. The fiber slurry was centrifuged once again, and the solid fraction was stored in vacuum-sealed plastic bags at $4^{\circ} \mathrm{C}$. Steam-exploded samples derived from residence times of 7.5 and 15 min were labeled with the acronyms SEB-7.5 and SEB-15, respectively.

\section{Mechanical refining}

Mechanical refining was used as a reference to evaluate the impact of steam explosion on sugarcane bagasse structure and composition. Sugarcane bagasse was first processed in a Sprout Waldron refiner and further refined by 4,000 revolutions at $10 \mathrm{wt} . \%$ in a PFI mill. The resulting material was labeled as mechanically refined bagasse (MRB).

\section{Delignification}

Alkaline delignification was carried out on both steam-exploded and mechanically refined sugarcane bagasse according to Rocha et al. (2012). Briefly, fibers were suspended in aqueous $0.3 \mathrm{~mol} \mathrm{~L}-1 \mathrm{NaOH}$ to reach 5 wt.\% WIS. The suspension was heated up to $80{ }^{\circ} \mathrm{C}$ and kept under vigorous and constant stirring for $60 \mathrm{~min}$. Then, the reaction was quenched by a 10-fold dilution with tap water at room temperature. The solids were recovered by centrifugation and washed several times with tap water until $\mathrm{pH}$ 7.0.

After alkaline delignification, samples were suspended in $0.05 \mathrm{~mol} \mathrm{~L}^{-1} \mathrm{NaClO}$ solution to reach 5 wt.\% WIS. The suspensions were heated up to $70{ }^{\circ} \mathrm{C}$ and kept under vigorous and constant stirring for 60 or $180 \mathrm{~min}$. For the $180 \mathrm{~min}$ bleaching procedure, a new batch of fresh aqueous $\mathrm{NaClO}$ was added at every $60 \mathrm{~min}$. Then, the reactions were quenched with 10-fold tap water volume at room temperature $\left(25^{\circ} \mathrm{C}\right)$. The solids were recovered by centrifugation and washed several times with tap water until $\mathrm{pH}$ 7.0. 
Enzymatic hydrolysis was carried out with an equivalent of $320 \mathrm{~g}$ of Novozyme 476 (Novozymes $^{\circledR}$ ) per ton of bleached pretreated sugarcane bagasse (MRB or SEB). The reaction was performed at $50{ }^{\circ} \mathrm{C}$ and $2.5 \mathrm{wt} . \%$ WIS in sodium acetate buffer $\left(0.05 \mathrm{~mol} \mathrm{~L}^{-1}\right) \mathrm{pH} 4.5$ as previously described by Tarrés et al. (2016). After $180 \mathrm{~min}$, the reaction was quenched by heating at $80{ }^{\circ} \mathrm{C}$ for 10 min followed by addition of $3 \mathrm{~g} \mathrm{~L}^{-1} \mathrm{NaOH}(2.5 \mathrm{wt} \%$ WIS) at constant stirring. Then, the suspension was centrifuged, and the solids were washed exhaustively with tap water until $\mathrm{pH} 7.0$.

202

203

\section{High-pressure homogenization}

204

The suspended solids were adjusted to $1 \mathrm{wt} . \%$ WIS after enzymatic hydrolysis using tap water, and mechanically processed through a high-pressure homogenizer (PANDA Plus 2000 homogenizer - Gea Niro Soavi, Italy) for a total of 9 passes (3 at 300 bar, 3 at 600 bar, and 3 at 900 bar) according to the methodology described by Tarrés et al. (2016). The resulting fiber suspension was kept at $4{ }^{\circ} \mathrm{C}$ until analysis.

209

\section{Chemical composition analysis}

211 Lignocellulosic materials were analysed for their chemical composition using the 212 recommendations of the National Renewable Energy Laboratory (NREL, Golden, USA). 213 Moisture contents were determined in an infrared balance at $105^{\circ} \mathrm{C}$ until constant mass. Ash 214 contents were determined in a muffle at $575{ }^{\circ} \mathrm{C}$ for $4 \mathrm{~h}$ according to the NREL/TP-510-42622 215 method. Total extractives were obtained from a two-stage extraction system in a Soxhlet 216 apparatus, first with water ( $16 \mathrm{~h}$ ) and then with ethanol $95 \%$ for $24 \mathrm{~h}$ according to the NREL/TP$217 \quad 510-42619$.

Total lignin and carbohydrate contents were determined after dilution sulfuric acid hydrolysis following the NREL/TP-510-42618 method. Samples were initially treated with $72 \%$ $\mathrm{H}_{2} \mathrm{SO}_{4}\left(\mathrm{v} \mathrm{v}^{-1}\right)$ for $60 \mathrm{~min}$ at $30^{\circ} \mathrm{C}$. Then, the material was diluted to $3 \% \mathrm{H}_{2} \mathrm{SO}_{4}\left(\mathrm{v} \mathrm{v}^{-1}\right)$, conditioned at $121^{\circ} \mathrm{C}$ for $60 \mathrm{~min}$ and filtered through a medium porosity sintered glass crucible. Acid-insoluble lignin was determined gravimetrically, while acid-soluble lignin was quantified by ultraviolet spectroscopy at $240 \mathrm{~nm}$. Carbohydrates and their corresponding dehydration byproducts were determined in the resulting acid hydrolysates by high-performance liquid chromatography using a Shimadzu HPLC model LC10AD (Kyoto, Japan). The system was equipped with a SIL10A autosampler, a DGU 14A mobile phase degasser, a CTO 10A heating oven, and a RID10A refractive index detector. Analyses were carried out at $65^{\circ} \mathrm{C}$ in a Hi-Plex $\mathrm{H}$ column (Agilent, $300 \times 7.7 \mathrm{~mm}$ ) preceded by a Hi-Plex $\mathrm{H}^{+}$column (Agilent, $50 \times 7.7 \mathrm{~mm}$ ), 
which were eluted with $5 \mathrm{mmol} \mathrm{L}^{-1} \mathrm{H}_{2} \mathrm{SO}_{4}$ at a flow rate of $0.6 \mathrm{~mL} \mathrm{~min}^{-1}$ (Pereira Ramos and 230 Domingos Fontana 2004). Quantification was based on calibration curves that were build using 231 primary standards for cellobiose, glucose, xylose, arabinose and acetic acid in the 0.05 to 2 $232 \mathrm{mg} \mathrm{mL}^{-1}$ concentration range. Mass balance calculations considered the loss of one water 233 molecule during hydrolysis, generating correction factors that corresponded to 0.95 for 234 cellobiose, 0.90 for glucose, 0.88 for xylose and arabinose and 0.70 for acetic acid.

235

\section{Transmission Electron Microscopy}

Morphological analyses and dimension measurements after high-pressure homogenization were carried out by transmission electron microscopy (TEM). Samples (5 $\mu \mathrm{L}$ of $10 \mu \mathrm{g} \mathrm{mL}^{-1}$ fiber suspensions) were deposited in formvar grids coated with carbon. After $60 \mathrm{~min}$, the excess liquid was absorbed with a filter paper strip and the sample was dried at $25^{\circ} \mathrm{C}$ for $48 \mathrm{~h}$. Analyses were performed in Jeol JEM-1400 Plus TEM instrument operating with an electron acceleration voltage of $100 \mathrm{keV}$, and images were recorded with a TVIPS F216 TemCam camera ( $2040 \times 2040$ px). Fiber measurements were carried out using the ImageJ software.

245

\section{Rheology}

Rheological properties of LNC suspensions were measured using a Thermo Scientific Haake Rheostress 1 rheometer (Karlsruhe, Germany) that was equipped with cone and plate geometry sensor $\left(40 \mathrm{~mm}\right.$ in diameter, cone $\left.2^{\circ}\right)$. The gap between the plates was $1 \mathrm{~mm}$ at $25^{\circ} \mathrm{C}$. Steady-state viscosity measurements were carried out in a range of shear rates from 0.01 to $1000 \mathrm{~s}^{-1}$. Changes in viscosity were recorded in nanofiber suspensions at the following concentrations: $1.0,2.5 ., 5.0$ and $10 \mathrm{mg} \mathrm{mL}^{-1}$. Viscosity values at the shear rate of $1000 \mathrm{~s}^{-1}$ were used to calculate both specific $\left(\eta_{\mathrm{sp}}\right)$ and relative $\left(\eta_{\mathrm{rel}}\right)$ viscosities using Equations 1 and 2 (Huggins 1942; Kraemer 1938),

$$
\begin{aligned}
& \eta_{s p}=\frac{\eta-\eta_{0}}{\eta_{0}} \\
& \eta_{\text {rel }}=\frac{\eta}{\eta_{0}}
\end{aligned}
$$
where $\eta$ is the suspension viscosity at the shear rate of $1000 \mathrm{~s}^{-1}$ and $\eta_{0}$ is the viscosity of deionized water. Then, these values were plotted against the sample concentration $(c)$ using Equations 3 and 4, respectively,

$$
\begin{aligned}
& \frac{\eta_{s p}}{c}=[\eta]+k_{1}[\eta]^{2} c \\
& \frac{\ln \eta_{r e l}}{c}=[\eta]+k_{2}[\eta]^{2} c
\end{aligned}
$$


were $\mathrm{k}_{1}$ is the Huggins's constant, $\mathrm{k}_{2}$ is the Kraemer's constant and [ $\eta$ ] is the intrinsic viscosity. Real [n] values were calculated using the average of the two calculated intercepts.

The aspect ratios $(f)$ of LCNF (length/diameter relationship) were predicted from the [n] values according to Equation 5 (Simha 1940). Hence, the Simha's plot was used to correlate the achieved $[\eta]$ values with their corresponding $f$ values.

267

268

$$
[\eta]=\frac{f^{2}}{15(\ln 2 f-1.5)}+\frac{f^{2}}{5(\ln 2 f-0.5)}+\frac{14}{15}
$$

269

\section{X-ray powder diffraction}

X-ray diffraction (XRD) measurements were performed in a Shimadzu XRD 6000 diffractometer that was operated at $40 \mathrm{kV}$ and $30 \mathrm{~mA}$ with $\mathrm{Cu} \mathrm{Ka}$ radiation $(\lambda=0.15418 \mathrm{~nm})$. Samples were lyophilized, placed on aluminum stubs, and measured to estimate crystallinity as described by Chen et al. (2007). Data were collected in the reflectance mode in the $2 \theta$ range of $10-40^{\circ}$ at $0.5^{\circ} \mathrm{min}^{-1}$. Diffractograms were adjusted with the Gaussian model (Fityk 0.8.0) and the crystallinity index (Crl, \%) was calculated using Equation 7 (Hermans et al. 277 1946),

$$
\operatorname{CrI}(\%)=100\left(\frac{A_{c}}{A_{t}}\right)
$$

where $A_{c}$ corresponds to the total crystalline area and $A_{t}$ is the total area (amorphous and 280 crystalline) under the diffractograms.

\section{Results and discussion}

\section{Chemical characterization of pretreated cane bagasse}

284 The chemical composition of the starting material is given in Table 1. In average, 285 sugarcane bagasse contained $40.6 \%$ glucans, $21.6 \%$ xylans, $21.0 \%$ total lignin (acid-soluble plus acid-insoluble insoluble lignins), $4.2 \%$ extractives and $2.8 \%$ ashes. This composition agrees with other reports found in the literature, in which sugarcane bagasse was characterized using the same analytical methods (Carrasco et al. 2010; Moraes Rocha et al. 2011; Silva et al. 2010; Szczerbowski et al. 2014). Nonetheless, small variations are expected in these values due to factors such as sample origin, presence of impurities, and impact of cultivation conditions, as well as differences in the technologies used for harvesting and sugarcane processing. 
293 Table 1. Chemical composition of native (SB), mechanically refined (MRB) and steam-exploded (SEB) sugarcane bagasse before and after alkaline delignification (AD) and alkaline delignification followed by hypochlorite bleaching for 60 (HB60) and 180 min (HB180).

\begin{tabular}{|c|c|c|c|c|c|c|c|c|c|c|c|}
\hline \multirow{2}{*}{ Components (\%) } & \multirow{2}{*}{ SB } & \multicolumn{2}{|c|}{ MRB } & \multicolumn{4}{|c|}{ SEB for $7.5 \mathrm{~min}$ at $195^{\circ} \mathrm{C}$} & \multicolumn{4}{|c|}{ SEB for $15 \mathrm{~min}$ at $195^{\circ} \mathrm{C}$} \\
\hline & & $\mathrm{AD}$ & HB180 & SEB7.5 & $A D$ & HB60 & HB180 & SEB15 & $A D$ & HB60 & HB180 \\
\hline Glucans & $40 \pm 1$ & $53 \pm 1$ & $54 \pm 1$ & $56 \pm 1$ & $77 \pm 1$ & $87 \pm 1$ & $84 \pm 1$ & $49 \pm 1$ & $79 \pm 1$ & $84 \pm 1$ & $82 \pm 2$ \\
\hline Xylans & $22 \pm 1$ & $18.4 \pm 0.3$ & $19 \pm 1$ & $3.4 \pm 0.2$ & $2.9 \pm 0.1$ & b.d.l. & b.d.l. & $2.0 \pm 0.3$ & $1.4 \pm 0.1$ & b.d.l. & b.d.l. \\
\hline Arabinosyl residues ${ }^{2}$ & $1.57 \pm 0.05$ & $1.5 \pm 0.1$ & b.d.l. & b.d.l. & b.d.l. & b.d.I. & b.d.l. & b.d.l. & b.d.l. & b.d.l. & b.d.l. \\
\hline Acetyl groups ${ }^{3}$ & $2.8 \pm 0.1$ & b.d.l. & b.d.l. & b.d.I. & b.d.I. & b.d.I. & b.d.l. & b.d.l. & b.d.l. & b.d.l. & b.d.I. \\
\hline Total lignin & 21.0 & 12.3 & 11.6 & 32.5 & 8.2 & 7.2 & 4.8 & 41.5 & 8.3 & 6.3 & 5.0 \\
\hline Acid-soluble & $0.02 \pm 0.01$ & $2.1 \pm 0.2$ & $5.6 \pm 0.1$ & $0.5 \pm 0.1$ & $1.1 \pm 0.1$ & $2.5 \pm 0.1$ & $2.1 \pm 0.1$ & $0.5 \pm 0.1$ & $1.1 \pm 0.1$ & $2.1 \pm 0.1$ & $2.0 \pm 0.5$ \\
\hline Acid-insoluble & $21 \pm 1$ & $10.2 \pm 0.1$ & $6.0 \pm 0.2$ & $32 \pm 1$ & $7.1 \pm 0.3$ & $4.7 \pm 0.2$ & $2.7 \pm 0.2$ & $41 \pm 1$ & $7.2 \pm 0.5$ & $4.2 \pm 0.5$ & $3.0 \pm 0.5$ \\
\hline Ashes & $2.8 \pm 0.3$ & $8.1 \pm 0.6$ & $5.5 \pm 0.5$ & $3.2 \pm 0.1$ & $7.3 \pm 0.2$ & $3.1 \pm 0.1$ & $7.2 \pm 0.3$ & $4.2 \pm 0.5$ & $7.6 \pm 0.6$ & $4.2 \pm 0.5$ & $8.9 \pm 0.3$ \\
\hline Total extractives & $4.2 \pm 0.5$ & n.d. & n.d. & n.d. & n.d. & n.d. & n.d. & n.d. & n.d. & n.d. & n.d. \\
\hline Water-soluble & $2.3 \pm 0.4$ & n.d. & n.d. & n.d. & n.d. & n.d. & n.d. & n.d. & n.d. & n.d. & n.d. \\
\hline Ethanol-soluble & $1.9 \pm 0.6$ & n.d. & n.d. & n.d. & n.d. & n.d. & n.d. & n.d. & n.d. & n.d. & n.d. \\
\hline Total (\%) & 94.4 & 93.3 & & 95.1 & 95.4 & 97.3 & 96.0 & 96.7 & 96.3 & 94.5 & 95.9 \\
\hline Mass yield (\%) & 100 & $65 \pm 4$ & $54 \pm 3$ & $59 \pm 4$ & n.d. & $33 \pm 4$ & $31 \pm 5$ & $57 \pm 6$ & n.d. & $32 \pm 4$ & $30 \pm 5$ \\
\hline
\end{tabular}

b.d.I., below the detection limit of the method; n.d., not determined;

$296{ }^{1}$ Measured as xylose in acid hydrolysates;

$297{ }^{2}$ Measured as arabinose in acid hydrolysates and present as substituents of the xylan backbone;

$298{ }^{3}$ Measured as acetic acid in acid hydrolysates and present as substituents of the xylan backbone. 
Sugarcane bagasse was subjected to different pretreatment conditions prior to highpressure homogenization to produce nanocellulose. Steam explosion is a pretreatment that is well-known to remove most of the hemicellulose component from biomass, resulting in steamtreated materials primarily composed of glucans (mostly cellulose) and lignin (Martino et al. 2017; Zhang et al. 2007). On the other hand, mechanical refining is not supposed to affect biomass chemical composition, but some ashes and/or extractives $(<1 \%)$ may be removed by cold water during Sprout Waldron defibrillation. Hence, after mild alkaline delignification and hypochlorite bleaching, enzymatic hydrolysis and high-pressure homogenization, SEB and MRB rendered bleached nanofibers with different hemicellulose contents (Agbor et al. 2011; Hendriks and Zeeman 2009). Delignification was required in this study because lignin interferes with enzymatic hydrolysis and impairs the effects of high-pressure homogenization during nanocellulose production (Lu et al. 2018; Rojo et al. 2015).

Alkaline delignification of MRB led to a $65.1 \%$ recovery of dry biomass. The resulting material exhibited lower hemicelluloses and lignin contents (Table 1), with $86 \%$ of glucans being retained in the alkali-insoluble material. During this process, lignin undergoes partial depolymerization and fragments are released to be solubilized in alkali in the form of phenolates, which are subsequently removed by filtration and washing. The recovered solids showed an increase in the ratio between acid-soluble lignin and acid-insoluble lignin, probably due to the reprecipitation of depolymerized fragments that were not removed even after extensive water washing. Acetyl groups were no longer detected after alkaline delignification, while the hemicellulose content (mostly xylans) decreased from 21.7 to $18.4 \%$. Also, there was an increase in the ash content of alkali-insoluble materials because sodium ions $\left(\mathrm{Na}^{+}\right)$were retained as salts by acidic functional groups that are found in both hemicelluloses and lignin. Hydroxyl groups possess high affinity for $\mathrm{Na}^{+}$(Budtova and Navard 2016) and can only be removed by ion exchange under acidic conditions. Also, residual lignin contains additional weak acid sites (carboxyl groups and phenolic acids) that would help retaining $\mathrm{Na}^{+}$by electrostatic interaction.

Hypochlorite bleaching for 60 min (MRB-HB60 in Table 1) was not enough to impart significant changes to the chemical composition of MRB fibers. By contrast, MRB bleaching for 180 min (MRB-HB180) improved fiber homogeneity, removed chromophores and reduced the hemicellulose content to undetectable levels, but its effect on delignification was not high due to fiber recalcitrance and to the relatively mild conditions applied in this process. Bleaching for $180 \mathrm{~min}$ resulted in a total mass loss of $46 \mathrm{wt} \%$ in relation to the starting material (dry basis). The amount of acid-insoluble lignin was reduced from $10.2 \%$ in alkali-washed cane bagasse to $6.0 \%$ with a concomitant increase in acid-soluble lignin from 2.1 to $5.6 \%$ (Table 1 ). 
small amounts of lignin that could be used to produce LNC by partial enzymatic hydrolysis followed by high-pressure homogenization.

Steam explosion of sugarcane bagasse at $195{ }^{\circ} \mathrm{C}$ for 7.5 or 15 min gave mass recoveries of $56.4 \pm 4.1 \%$ and $57.4 \pm 6.2 \%$ (dry basis), respectively (Table 1). As a result, the hemicellulose content of sugarcane bagasse (mostly xylan) decreased from $22 \%$ to 3.4 and $2.0 \%$ while acetyl groups and arabinosyl residues were not detectable after pretreatment, suggesting the recovery of undecorated xylan fragments of relatively low molecular mass. Glucan recoveries were 83.1 and $70.3 \%$ for these two reaction times, respectively, revealing much higher sugar losses for pretreatments carried out for 15 min (SEB-15 in Table 1). Total lignin contents in steam-exploded materials increased from $21.0 \%$ in untreated sugarcane bagasse to 32.5 and $41.5 \%$ in SEB-7.5 and SEB-15, respectively. These values correspond to total lignin recoveries of 91.9 and $113.4 \%$ in relation to the chemical composition of sugarcane bagasse, indicating that hydrolysis prevailed over condensation reactions at shorter residence times into the steam reactor. By contrast, longer residence times led to the formation of both humins and/or pseudo-lignin, as already reported in the literature (Aarum et al. 2018). Humins are condensed acid-insoluble macromolecular structures that are formed from carbohydrate dehydration by-products at high pretreatment severities, while pseudo-lignin arises from contaminations such as resin oils and fats and from condensation reactions involving cinnamic acid derivatives, organic acids and furan compounds. When present in high amounts, these acid-insoluble extraneous materials behave as acid-insoluble lignin, causing an overestimation in its quantitative analysis. Ash contents increased slightly after pretreatment, and this appeared to be another effect of hemicellulose removal.

Alkaline delignification of both SEB-7.5 and SEB-15 dropped their total lignin content to 8.2 and $8.3 \%$, respectively, having similar impact on both acid-soluble and acid-insoluble lignin contents. The hemicellulose content in both alkali-insoluble materials was further reduced to $2.9 \%$ for SEB-7.5 and $1.4 \%$ for SEB-15. This incomplete hemicellulose removal may have been due to the temperature $\left(80^{\circ} \mathrm{C}\right)$ and $\mathrm{NaOH}$ concentration $\left(0.3 \mathrm{~mol} \mathrm{~L}^{-1}\right)$ used for delignification, compared to harsher conditions already described in the literature (Kamali and Khodaparast 2015; Thompson et al. 2001). Both ash and glucan contents were not affected by alkaline delignification and their increase in alkali-insoluble materials was proportional to the decrease of other fiber constituents. Alkaline washing followed by hypochlorite bleaching for 60 and 180 min resulted in an overall mass loss of 67 and $69 \%$ in relation to the dry mass of sugarcane bagasse, respectively. Bleaching of alkali-washed SEB-7.5 for 60 or $180 \mathrm{~min}$ produced fibers with total lignin contents of 7.2 and $4.8 \%$, respectively, and by doubling the pretreatment time to $15 \mathrm{~min}$ (SEB-15), alkali-washed hypochlorite-bleached fibers with total

372 lignin contents of 6.3 and $5.0 \%$ were obtained. Hemicellulose contents were again under 
373 undetectable levels, while higher brightness could only be observed after bleaching for $374180 \mathrm{~min}$.

375 Compared to MRB, alkaline delignification and bleaching for 180 min were more 376 effective for SEB, but the resulting bleached materials still contained relatively high total lignin 377 contents (Table 1). However, as already observed for MRB, acid-soluble lignin corresponded 378 to $35-40 \%$ of the total lignin content of fully bleached materials (HB180 in Table 1), while for 379 alkaline delignification alone its contribution was much lower, falling the range of 13.2 to $13.4 \%$ 380 of the corresponding total lignin contents.

381 The steam explosion, alkaline delignification and bleaching procedures described 382 above generated five bleached materials for LNC production. With this, the effects of lignin and 383 hemicellulose contents were accessed on the efficiency of LNC isolation by enzymatic 384 hydrolysis followed by high-pressure homogenization.

385

\section{Enzymatic hydrolysis of partially delignified fibers}

387 All bleached biomasses were subjected to the same enzymatic hydrolysis condition 388 using a commercial endoglucanase preparation. Enzymatic hydrolysis was used to decrease 389 the fiber-fiber entanglement and consequently reduce the energy required for mechanical 390 defibrillation (Kargarzadeh et al. 2017; Xie et al. 2018). Furthermore, treatment by 391 endoglucanases for short reaction times (180 $\mathrm{min}$ ) are not expected to result in significant 392 mass losses due to their classical mode of action, which limits reducing sugar release by acting 393 at the more accessible regions of the cellulose supramolecular structure (amorphous 394 cellulose). Then, enzyme-treated fiber suspensions were passed through a high-pressure 395 homogenizer under the same experimental conditions. The presence of nanofibers was 396 indicated by achieving viscous suspensions with a gel-like appearance without evidence for macroscopic aggregates. Also, there was no significant change in chemical composition after mechanical treatment, as indicated in Figure 2. 


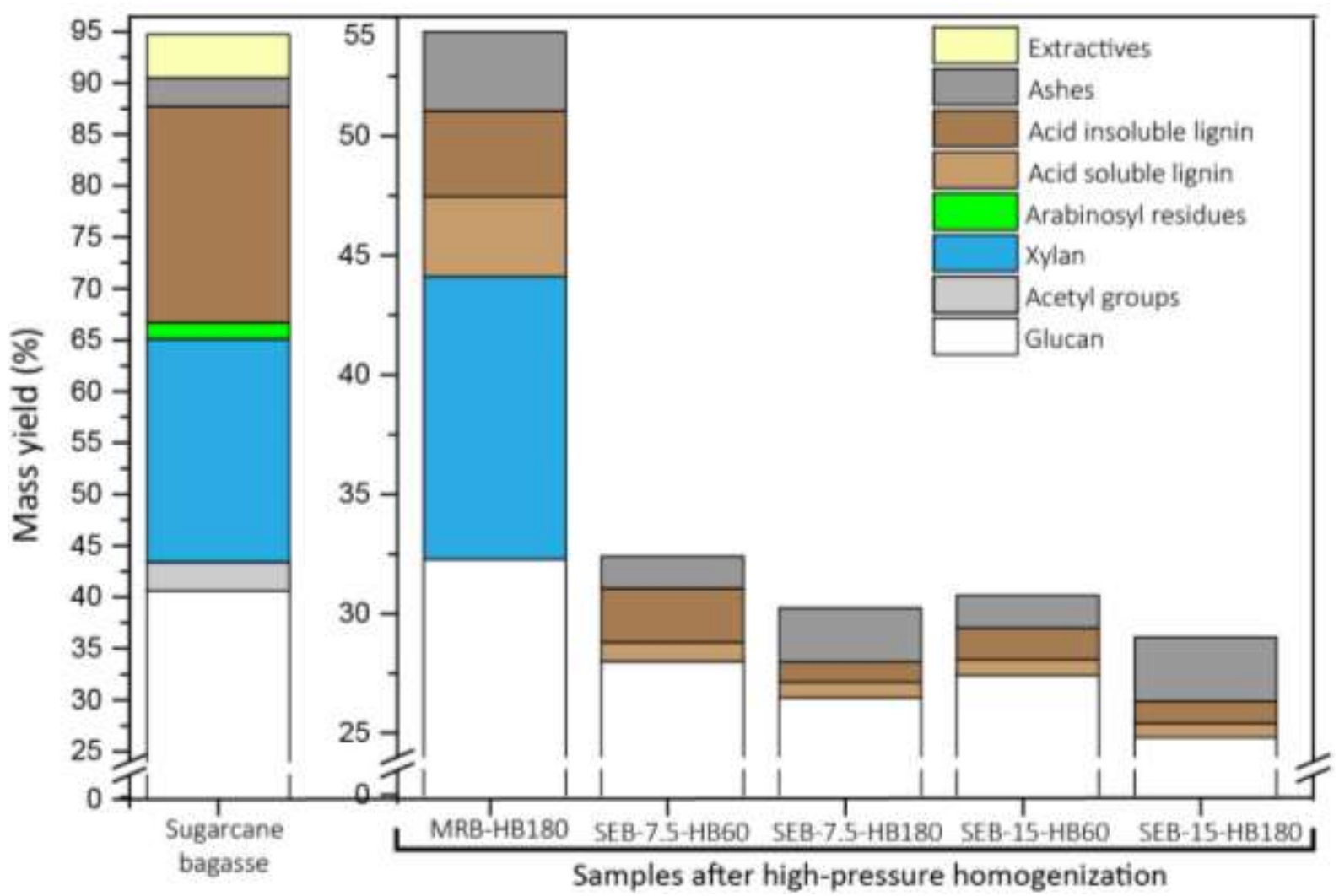

Figure 2. Chemical composition of sugarcane bagasse compared to lignocellulose nanomaterials that were obtained after mechanical refining or steam explosion ( 7.5 and 15 min at $195^{\circ} \mathrm{C}$ ), followed by alkali washing, hypochlorite bleaching (60 and $180 \mathrm{~min}$ ), enzymatic hydrolysis, and high-pressure homogenization.

\section{Rheological characterization after high-pressure homogenization}

Changes in rheological behavior are expected after reduction of fiber diameter from a micrometric to a nanometric scale, forming a gel-like structure in water that is organized by semi-permanent hydrogen bonding networks (Nguyen et al. 2015; Samaniuk et al. 2011). With a decrease in fiber diameter, there is a corresponding increase in surface area and the

411 interaction with water promotes their orientation when exposed to a laminar flow. Hence, the 412 minimum amount of mass required to reach the gel point is considerably reduced. By gathering 413 knowledge about the gel point, one can estimate fiber dimensions by determining their corresponding aspect ratio (Delgado-Aguilar et al. 2015a; Liu et al:. 2011; Varanasi et al. 2013). Accurate fiber dimensions in nanoscale (especially length) are very hard to achieve by 416 electron microscopy because cellulose nanofibers tend to aggregate during sample 417 preparation for analysis. By contrast, rheological measurements and sedimentation techniques are fast and robust alternatives to access the properties of cellulose nanomaterials because 
419 they do not require drying and produce results that are more representative of the entire fiber 420 population (Delgado-Aguilar et al. 2015a; Liu et al. 2011; Varanasi et al. 2013).

421 The aspect ratio of LNC isolated in this work was first investigated by employing 422 rheological measurements. Viscosity changes at steady state as a function of the shear rate 423 are shown in Figure 3 for 10.0, 5.0, 2.5 and $1.0 \mathrm{mg} \mathrm{mL}^{-1}$ LNC suspensions. Higher 424 concentrations resulted in higher viscosities for all dilutions throughout the shear rate curve, 425 indicating the formation of a more rigid fiber network. Also, sample viscosity decreased with 426 an increase in shear rate, exhibiting a typical shear thinning behavior.

$427 \quad$ Each shear-thinning curve could be divided in five regions. In region I, fibers orient 428 themselves slowly along the shear direction under low shear force, causing a gradual decrease 429 in viscosity. In region II, the viscosity rate decreases, exhibiting lower changes in viscosity with 430 an increase in shear rate probably due to the formation of a more entangled fiber network. In 431 region III, as the shear rate increases continuously, shear forces cause the tangled network to 432 break into individual nanofibers, leading to a decrease in the system viscosity. In region IV, 433 another plateau appears because most of the entangled network was interrupted, with the 434 formation of a well-oriented nanofibrillar structure. The results described above are similar to 435 those observed by Delgado-Aguilar et al. (2015a) for cellulose nanoparticles in water 436 suspension. LCNF suspensions derived from MRB-HB180 (Figure 3a) showed higher 437 viscosities than those derived from steam-exploded materials (Figures $3 b$ to $3 e$ ). This 438 difference in viscosity can be attributed not only to differences in the LCNF aspect ratio, but 439 also to differences in their chemical composition. As discussed before, LCNF from MRB440 HB180 had a hemicellulose content higher than that of LCNF from SEB-HB and their greater 441 hydrophilicity may have influenced trends in sample viscosity. 

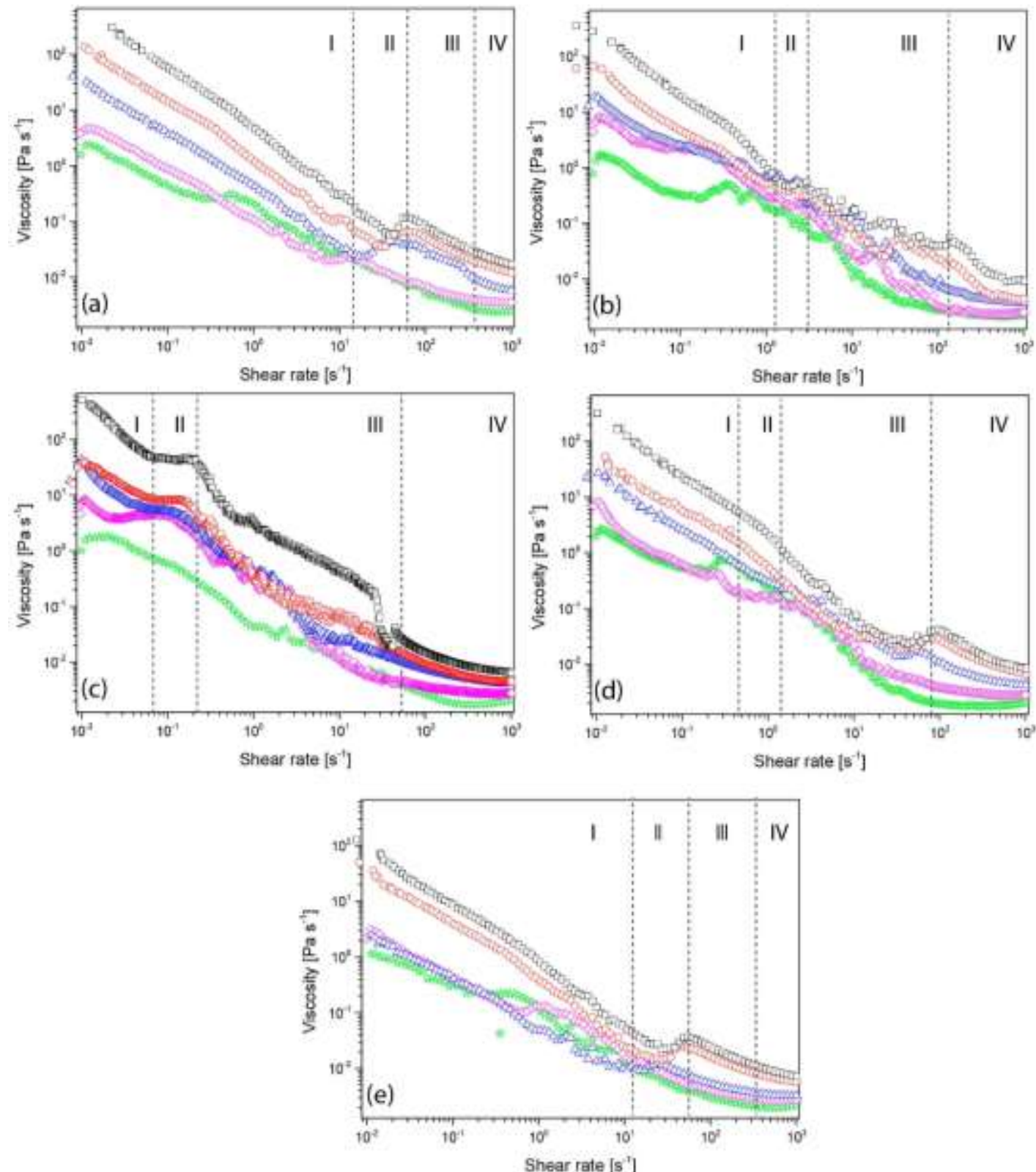

444 Figure 3. Steady-state viscosity vs. shear rate of (a) MRB-HB180, (b) SEB-7.5-HB60, (c) SEB445 7.5-HB180, (d) SEB-15-HB60 and (e) SEB-15-HB180 suspensions with concentrations of $4461.0 \mathrm{mg} \mathrm{mL}^{-1}$ (black squares), $2.5 \mathrm{mg} \mathrm{mL}^{-1}$ (red circles), $5 \mathrm{mg} \mathrm{mL}^{-1}$ (blue triangles) and $44710 \mathrm{mg} \mathrm{mL}^{-1}$ (olive stars) at $25^{\circ} \mathrm{C}$. At low concentrations and low shear rates, viscosity could 448 not be measured precisely due to limitations in the rheometer sensitivity.

To access the LCNF aspect ratio, $\ln \eta_{\mathrm{rel}} / c$ and $\ln \eta_{\mathrm{sp}} / c$ values were plotted against sample concentration at a shear rate of $1000 \mathrm{~s}^{-1}$ (Figure 4-A to 4-E). With this, the $y$-axis 451 intercepts from Equations 3 and 4 yielded the corresponding apparent intrinsic viscosities [n] 452 and their averages indicated the true [n] value, which was 500, 644, 517, 600 and 392 for 

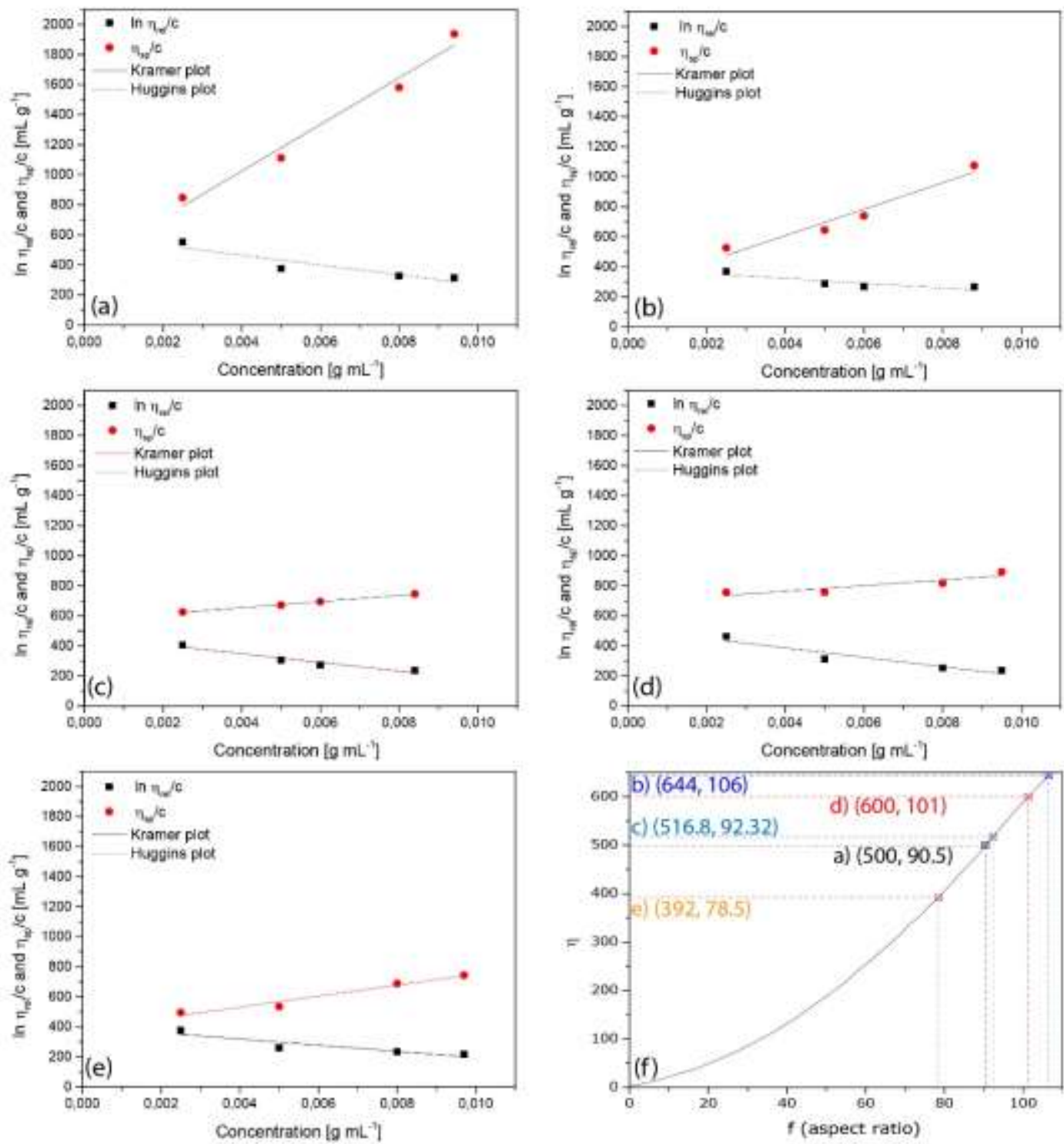

Figure 4. Values of In $\eta_{\mathrm{rel}} / \mathrm{c}$ and $\eta_{\mathrm{sp}} / \mathrm{c}$ and Kraemer and Huggins' plots for ultra-homogenized fibers suspensions: (a) MRB-HB180, (b) SEB-7.5-HB60, (c) SEB-7.5-HB180, (d) SEB-15458 HB60 and (e) SEB-15-HB180 at a shear rate of $230 \mathrm{~s}^{-1}$ at $25^{\circ} \mathrm{C}$ and (d) Simha's plot used to estimate the aspect ratio (f) of ultra-homogenized fibers.

The plotted values of [ $\eta$ ] vs. f using the Simha's equation (see Material and Methods for further clarification) are shown in Figure 4f. Simha's plot was presented in the form of a parabola, in which [ $\eta$ ] gradually increased as $f$-values increased. By interpolating the values of [n] in the Simha's plot, the following f values were obtained: 90.5 for MRB-HB180, 106.0 for 
465 SEB-7.5-HB60, 92.3 for SEB-7.5-HB180, 101.0 for SEB-15-HB60 and 78.5 for SEB-15466 HB180. According to the TAPPI WI 3021 standard, all these aspect ratios ( $\mathrm{f}$ values greater 467 than 50) fall in the cellulose nanofibril category. All members of the SEB group, except SEB15468 HB180, presented an aspect ratio slightly larger than that of MRB group, indicating fibers of 469 larger length and/or smaller diameter. The SEB-15-HB180 group showed an aspect ratio 470 significantly lower than all other materials, suggesting the occurrence of fibers of shorter length 471 and/or larger diameter.

$472 \quad$ Figure 5 shows the TEM micrographs of lignocellulose micro and nanofibrils. In Figure $4735 \mathrm{a}$, the observed nanofibers had width values of $11.7 \pm 23.5 \mathrm{~nm}$ for MRB HB180, $160.0 \pm 80.2$ $474 \mathrm{~nm}$ for SEB-7.5-HB60, $28.0 \pm 12.3 \mathrm{~nm}$ for SEB-7.5-HB180, $16.3 \pm 4.4 \mathrm{~nm}$ for SEB-15-HB60 475 and $16.2 \pm 7.3 \mathrm{~nm}$ for SEB-15-HB180. Most of the nanofibers appeared as bundles or 476 agglomerates with widths from 10 to $40 \mathrm{~nm}$, except those of the SEB-7.5 group, which had a 477 higher microfiber content. The presence of microfibers in the latter group corroborated the 478 aspect ratio that was obtained by statistical modeling using the Simha's equation (Figure 4). 479 The precise determination of length was complicated because nanofibers were strongly 480 aggregated or twisted, even after the homogenization process. This highly entangled network 481 of micro and nanofibers had a significant influence on their viscoelastic rheological properties 482 in aqueous suspensions. Fibers with reduced length of 100-400 nm and widths around $16 \mathrm{~nm}$ 483 were only observed in group SEB-15 (Figures $5 \mathrm{~d}$ and $5 \mathrm{e}$ ) and these could be classified as 484 CNC of according to the TAPPI WI 3021 standard. 

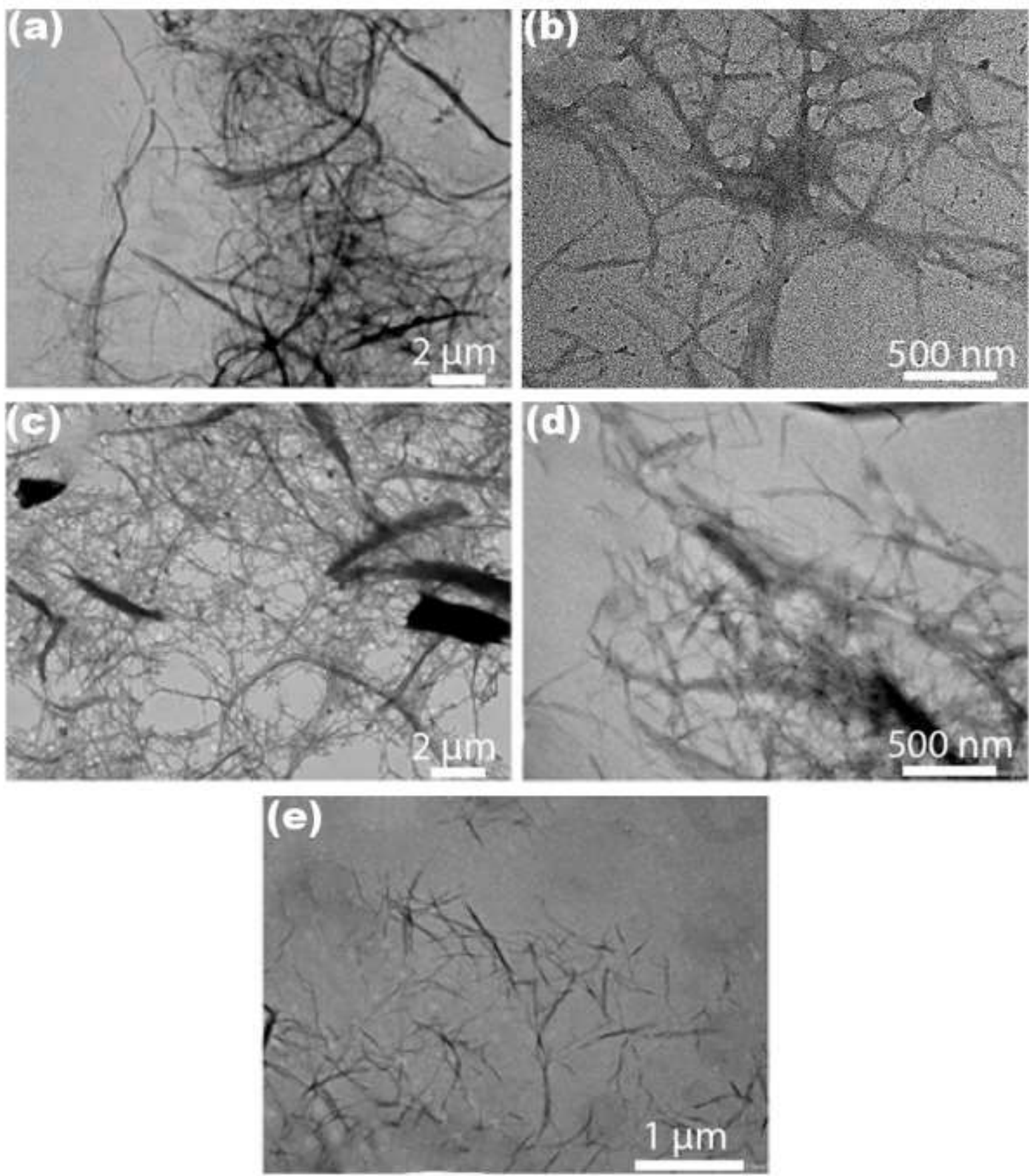

Figure 5. TEM micrographs of (a) MRB-HB180, (b) SEB-7.5-HB60, (c) SEB-7.5-HB180, (d) 488 SEB-15-HB60 and (e) SEB-15-HB180.

TEM analysis allowed to observe the presence of unexpected particles of spherical morphology in the SEB-7.5-HB60 nanofiber suspension. However, sample had to be contrasted with uranyl acetate to improve their visualization (Figure 6). The average diameter of the spherical particles was $85 \pm 37 \mathrm{~nm}$. These nanoparticles seemed to have a high adsorption affinity for the nanofibers because they persisted in the sample even after 
exhaustive washing with ultrapure water. We hypothesized that these round nanoparticles

496 were coalesced lignin fragments that were produced during steam explosion. Indeed, Jiang et 497 al. (2018) showed that spherical lignin nanoparticles are produced when the fiber diameter of 498 lignified fibers are reduced to the nanoscale by intense mechanical defibrillation.

499

500

501

502

503

504

505

506

507

508

509

510

511

512

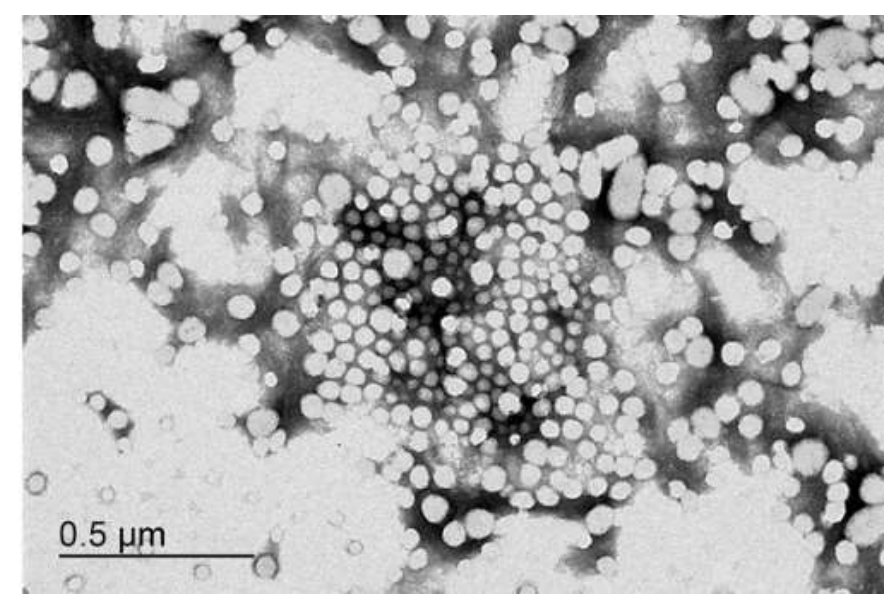

Figure 6. TEM micrograph of SEB-7.5-HB60 exhibiting agglomerated spherical nanoparticles. Visualization was improved by contrast using uranyl acetate.

The X-ray diffractograms of lyophilized samples after high-pressure homogenization are shown in Figure 7. All samples exhibited four main diffraction peaks around $15.2^{\circ}, 16.7^{\circ}$ and $22.6^{\circ}$, corresponding to the crystallographic planes $1 \overline{10,110}$ and 200 of cellulose I, respectively. Steam explosion, alkaline delignification, hypochlorite bleaching, enzymatic hydrolysis and mechanical refining did not cause noticeable changes in the position of the diffraction peaks, revealing that these treatments do not alter the crystalline structure of cellulose. However, LCNF materials with slightly higher crystallinity indexes (Crl) were isolated when steam explosion was carried out for longer residence times of $15 \mathrm{~min}$. 


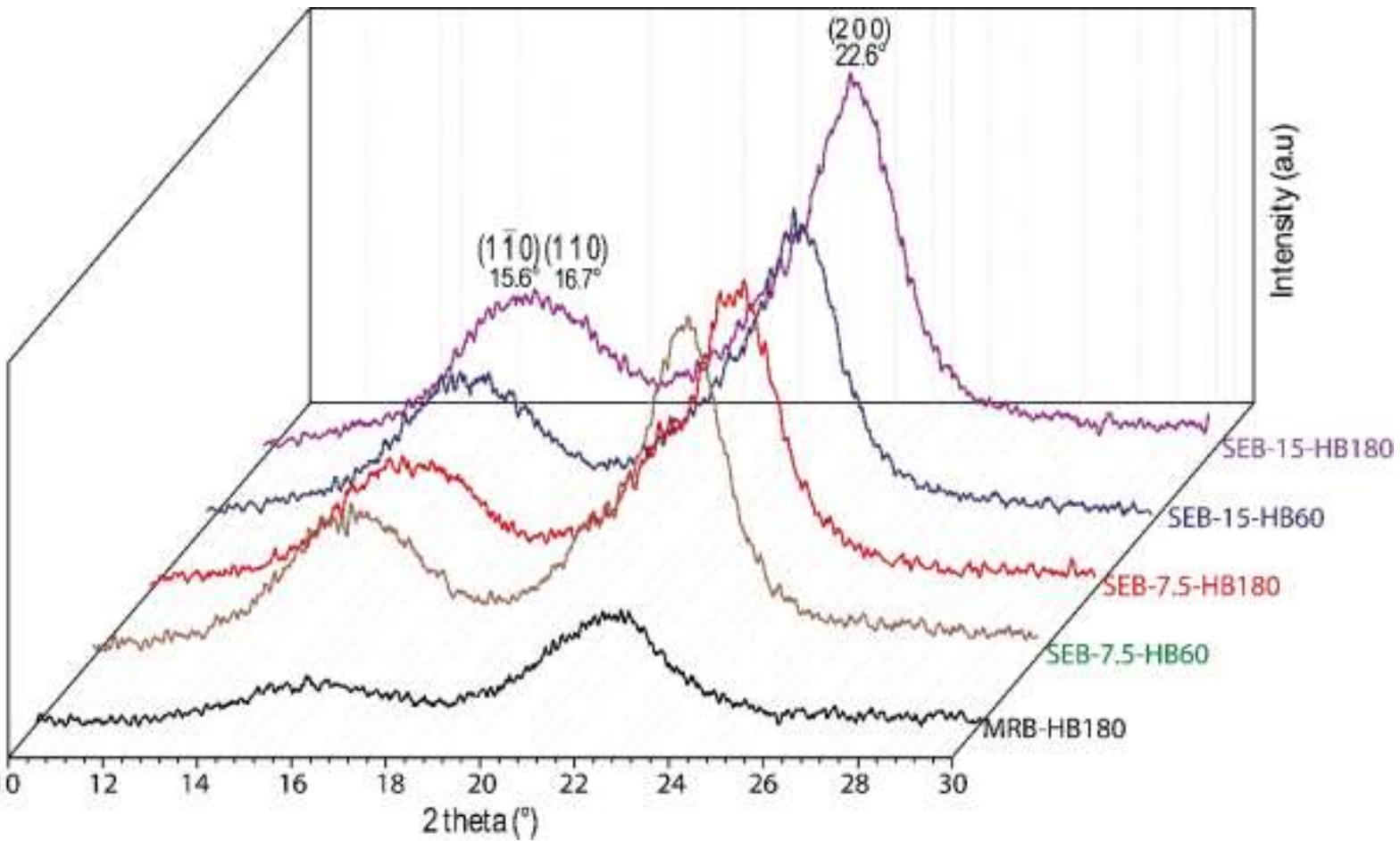

513

514

515

516

517

518

519

520

521

522

523

524

525

526

527

528

529

530

531

532

Fig. 7. X-ray patterns of high-pressure homogenized samples

The Crl values calculated for MRB, SEB-7.5-HB60, SEB-7.5-HB180, SEB15 HB60 and SEB15 HB180 were $68.5 \%, 72.7 \%, 76.2 \%, 75.8 \%$ and $77.0 \%$, respectively. The Crl variation from $68.5 \%$ of MRB HB180 to around $76.0 \%$ for SEB-HB180 materials suggest that more drastic pretreatment conditions led to a more extensive removal of hemicelluloses and amorphous cellulose mainly by partial acid hydrolysis. Also, the highest Crl value of SEB-15HB180 corroborates the observation by TEM of cellulose nanoparticles with a typical aspect ratio of CNC.

The dimensions, aspect ratio and crystallinity index of the obtained LCNF, compared to the literature data for nanocelluloses obtained from steam-exploded sugarcane bagasse, are summarized in Table 4. Although these works use steam explosion and the same biomass source, the post-treatment methodology for nanocellulose isolation was different, producing materials with low lignin content $(<1 \%)$ and some degree of surface derivatization (TEMPO oxidation and esterification with sulfuric acid). No studies were found using steam explosion followed by alkaline delignification, hypochlorite bleaching, enzymatic hydrolysis, and highpressure homogenization to isolate nanocelluloses with different lignin contents from sugarcane bagasse. 
Table 4 - Comparison of lignonanocelluloses obtained in this work with data available in the literature

\begin{tabular}{|c|c|c|c|c|c|c|c|c|}
\hline Sample & Biomass & Method & $\begin{array}{c}\text { Total lignin } \\
(\%)\end{array}$ & $\begin{array}{l}\text { Diameter } \\
(\mathrm{nm})\end{array}$ & $\begin{array}{l}\text { Length } \\
(\mathrm{nm})\end{array}$ & $f$ & $\begin{array}{l}\mathrm{Crl} \\
(\%)\end{array}$ & Ref. \\
\hline 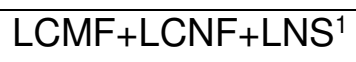 & \multirow{5}{*}{ Cane bagasse } & $\mathrm{SE}+\mathrm{AD}+\mathrm{HB}+\mathrm{EH}+\mathrm{HPH}$ & 7.2 & $160 \pm 80$ & 400 to $>1000$ & 106 & 72.7 & \multirow{5}{*}{$\begin{array}{l}\text { This } \\
\text { work }\end{array}$} \\
\hline LCNF$^{2}$ & & $\mathrm{SE}+\mathrm{AD}+\mathrm{HB}+\mathrm{EH}+\mathrm{HPH}$ & 4.8 & $28 \pm 12$ & 500 to $>1000$ & 92.3 & 76.2 & \\
\hline $\mathrm{LCMF}^{2} \mathrm{LCNF}^{3}$ & & $\mathrm{SE}+\mathrm{AD}+\mathrm{HB}+\mathrm{EH}+\mathrm{HPH}$ & 8.4 & $16 \pm 4$ & 300 to $>1000$ & 101 & 75.8 & \\
\hline $\mathrm{LCNF}_{+} \mathrm{LCNC}^{4}$ & & $\mathrm{SE}+\mathrm{AD}+\mathrm{HB}+\mathrm{EH}+\mathrm{HPH}$ & 5.0 & $16 \pm 7$ & $100-400$ & 78.5 & 77.0 & \\
\hline LCNF $^{5}$ & & $\mathrm{MRB}+\mathrm{HB}+\mathrm{HPH}$ & 11.6 & $45 \pm 23$ & $>1000$ & 90.5 & 68.5 & \\
\hline CNF & \multirow{3}{*}{ Cane bagasse } & $\mathrm{SE}+\mathrm{HT}+\mathrm{H}_{2} \mathrm{O}_{2}+\mathrm{HSB}+\mathrm{UT}$ & -- & $20-40$ & -- & -- & 71.2 & 1 \\
\hline $\mathrm{CNC}$ & & $\mathrm{SE}+\mathrm{AD}+\mathrm{AH}$ & -- & $16 \pm 4$ & $201 \pm 60$ & $13^{*}$ & 81.6 & 2 \\
\hline CNF & & $\mathrm{SE}+\mathrm{EH}+\mathrm{HB}+\mathrm{HPH}$ & -- & $5-10$ & -- & -- & 68.1 & 3 \\
\hline LCNF & Wheat straw & $\mathrm{AD}+\mathrm{TEMPO}+\mathrm{MT}+\mathrm{EH}+\mathrm{HPH}$ & $8.9-18.2$ & $11.16-116$ & $139-705$ & $3.9-6.1^{*}$ & $44-53$ & 4 \\
\hline LCNF & Pinus sp TMP & $\mathrm{MT}+\mathrm{EH}+\mathrm{TEMPO}$ & $15,20 \& 25$ & $\sim 12$ & $>1000$ & $>83^{*}$ & -- & 5 \\
\hline LCNF & Cereal straws & $\mathrm{AD}+\mathrm{MT}+\mathrm{HE}+\mathrm{TEMPO}+\mathrm{HPH}$ & 13.31 & $6.81-14.52$ & $251-697$ & $36-48^{*}$ & 44.44 & 6 \\
\hline LCNF & Stone-ground pulp & $\mathrm{AD}+\mathrm{HB}+\mathrm{MT}+\mathrm{HPH}$ & $2.47-6.47$ & $\sim 35$ & $>1000$ & $>28^{*}$ & 45 & 7 \\
\hline $\mathrm{LCMF}+\mathrm{LCNF}+\mathrm{LNS}$ & Cane bagasse & $\mathrm{OS}+\mathrm{AD}+\mathrm{HB}+\mathrm{MG}$ & $0.1,2.4 \& 14.9$ & $32,27 \& 9$ & -- & -- & -- & 8 \\
\hline LCNF & Wheat straw & $\mathrm{AE}+\mathrm{MT}+\mathrm{MF}$ & $4,8 \& 16$ & $17,14 \& 13$ & $>1000$ & $>77^{*}$ & -- & 9 \\
\hline LCNF & Eucalyptus sp. & $\mathrm{MT}+\mathrm{TEMPO}+\mathrm{MT}+\mathrm{HPH}$ & -- & 13 & $>1000$ & $>76^{*}$ & -- & 10 \\
\hline
\end{tabular}

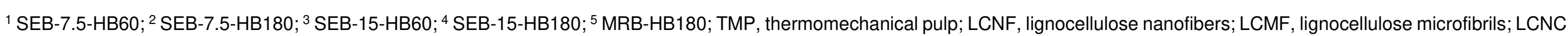

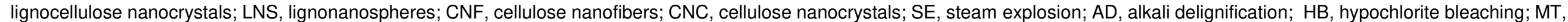

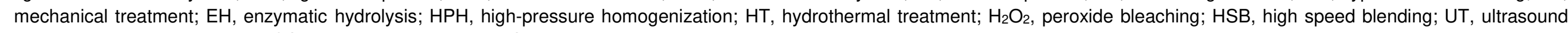
treatment; $\mathrm{AH}$, acid hydrolysis; OS, organosolv treatment; MG, micro-grinding; MF, micro-fluidization; $f$, aspect ratio; *, estimated aspect ratio from reported data.

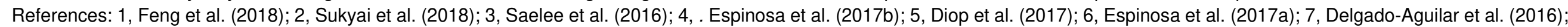
8, Jiang et al. (2018); 9, Gu et al. (2019); 10, . Herrera et al. (2018). 
Regarding fiber diameter, except for the SEB-7.5-HB60 group, all samples

542 had similar sizes $(10-20 \mathrm{~nm})$ compared to the data reported in the literature for both

543 CNC and CNF (Table 4). Specifically for CNF, most studies report diameter and

544 morphology measurements by electron microscopy, with no reference to fiber

545 length. This is because the accuracy of electron microscopy for length

546 measurements is hampered by aggregation and fiber interlacing ( $\mathrm{Li}, \mathrm{Wu}$ et al.

547 2015). In the present work, this problem was solved by performing rheological

548 analyzes to obtain CNF aspect ratios $(f)$. To compare our rheological LCNF aspect

549 ratios with data reported in the literature for other LCNF types, $f$ values were

550 estimated based on reported fiber diameters and average fiber lengths. In general,

551 the estimated $f$ values were lower than that of LCNC derived from SEB-15-HB180

552 (78.5). However, this difference can be explained by the presence of LCNF in this

553 sample and the effect of its higher fiber length on the corresponding $f$ value.

554 Regarding the crystallinity index, all samples presented values ( 72 to $77 \%$ ) close

555 to those reported in the literature (68 to $79 \%$ ) for both LCNF and LCNC.

$556 \quad$ Intense mechanical treatments are required for defibrillating biomass fibers

557 to the nanoscale and this can be achieved by increasing the number of passages

558 through the mill or the time and pressure used for homogenization (Khalil et al.

559 2014; Teo and Wahab 2020). However, excessive mechanical treatments may

560 cause a dramatic reduction in cellulose Crl (Potulski et al. 2016; Viana et al. 2019).

561 In this work, bleached SEB fibers were defibrillated to nanometric diameters using

562 nine passages through the mill, which is half that reported in the literature for

563 isolating LCNF from a variety of lignocellulosic materials (García et al. 2016;

564 Ghaemi et al. 2019; Hu et al. 2019; Lee et al. 2014). Also, bleached SEB LCNF

565 had $\mathrm{Crl}$ values higher than those reported in the literature (circa 45\% in Table 5).

566 This was probably due to the extent of hemicellulose removal during pretreatment

567 and to the hydrolytic action of endoglucanases over SEB bleached fibers. In

568 addition to LCNF, the presence of LCNC was also observed in both SEB-15-

569 derived nanomaterials, being predominant in HB180. No other work has

570 demonstrated the production of LCNC from SEB under conditions like those

571 applied in this study.

572 LCNFs have some advantages over lignin-free nanocelluloses, such as

573 ease of drying, redispersion and compatibility with more hydrophobic matrices.

574 Besides, its production process may offer significant economic advantages

575 compared to nanomaterials derived from fully bleached pulps. For example, the

576 cost of producing LCNF from kraft pulps using enzymatic hydrolysis followed by

577 high-pressure homogenization was estimated at 2000-5000 $€$ ton $^{-1}$ (Delgado- 
578 Aguilar et al. 2016), a very attractive price compared to alternatives already 579 available in a pre-industrial scale such as TEMPO-oxidized CNF, whose 580 production cost was recently estimated at 206,000 $€$ ton $^{-1}$ (Delgado-Aguilar et al. 581 2015b). Also, the use of agro-industrial wastes to produce LCNF can further 582 improve the process economics. For example, the cost of steam explosion for 583 materials such as sugarcane bagasse is estimated at around $60 €$ ton $^{-1}$ while the 584 bleaching costs are below $100 €$ ton $^{-1}$ (Cotana et al. 2015). Thus, LCNFs isolated 585 from steam-exploded sugarcane bagasse could be highly competitive with similar 586 products already available on the market.

\section{Conclusion}

Steam explosion of sugarcane bagasse followed by alkaline delignification, hypochlorite bleaching, enzymatic hydrolysis, and high-pressure homogenization, resulted in the isolation of lignocellulose nanomaterials with aspect ratios ranging from micro/nanofibers to nanocrystals. The high crystallinity index of these nanomaterials suggests good potential for applications as mechanical reinforcement agents. Also, the presence of lignin could be designed by changing parameters such as pretreatment severity and the extent of alkaline delignification or hypochlorite bleaching. With this, a range of alternative applications may be created by improving their interaction with more hydrophobic composite matrices

\section{Acknowledgments}

The authors are grateful to CNPq (grants 551404/2010-8 and 309506/2017-4) for providing financial support to carry out this study, as well as to Novozymes Latin America (Araucária, PR, Brazil) for donating the enzymes used for hydrolysis and to CYTED (Rede Nanocelia) for providing a fellowship to A.M.F. for a short stay at the University of Girona. This work was also financed in part by the Coordenação de Aperfeiçoamento de Pessoal de Nível Superior (CAPES, Brasil) - Finance Code 001. Authors also wish to acknowledge the financial support of the Spanish Ministry of Economy and Competitiveness to the project NANOPROSOST (reference CTQ2017-85654-C2-1-R). Dr. Marc Delgado-Aguilar

\section{Declarations}

\section{Conflicts of interest/Competing interests}


614 The authors declare that no conflict of interest is involved in this manuscript and

615 that they do not have any competing interests.

616

617 Availability of data and material

618 The authors made all data public in the international repository Zenodo. UdG

619 authors express their commitment to make them public in the UdG repository.

\section{Code availability}

622

Not applicable

623

\section{Authors' contributions}

625 Authors' contributions: LPR, MDA and CLP conceived the experimental design.

626 AMF and GROAT carried out pretreatment, isolation and characterization of 627 lignocellulosic materials. CLP performed microscopical, rheological and X-ray 628 diffraction analyses. QT helped in the execution of enzyme treatments and high629 pressure homogenization. AMF and CLP wrote the original manuscript draft. LPR and MDA revised the final version of the manuscript.

\section{Ethics approval}

633 Not applicable. This study does not involve humans and/or animals.

\section{Consent to participate}

636 All authors are authorized by their home institution and agreed to participate in the development of this research and in the preparation of this manuscript.

\section{Consent for publication}

640 All authors are aware of the manuscript submission and agree with its publication.

\section{References}

643 Aarum I, Devle H, Ekeberg D, Horn SJ, Stenstrøm Y (2018) Characterization of pseudo-lignin from steam exploded birch ACS Omega 3:4924-4931 https://doi.org/10.1021/acsomega.8b00381

Agbor VB, Cicek N, Sparling R, Berlin A, Levin DB (2011) Biomass pretreatment: fundamentals toward application Biotechnology Advances 29:675-685 https://doi.org/10.1016/j.biotechadv.2011.05.005

Arantes V, Saddler JN (2011) Cellulose accessibility limits the effectiveness of minimum cellulase loading on the efficient hydrolysis of pretreated lignocellulosic substrates Biotechnology for Biofuels 4:1-17 https://doi.org/10.1186/1754-6834-4-3 
Assis CA et al. (2017) Conversion economics of forest biomaterials: risk and financial analysis of CNC manufacturing Biofuels, Bioproducts and Biorefining 11:682-700 https://doi.org/10.1002/bbb.1782

Assis CA et al. (2018) Cellulose micro-and nanofibrils (CMNF) manufacturingfinancial and risk assessment Biofuels, Bioproducts and Biorefining 12:251$264 \mathrm{https}: / /$ doi.org/10.1002/bbb.1835

Bhatia L, Garlapati VK, Chandel AK (2019) Scalable technologies for lignocellulosic biomass processing into cellulosic ethanol. In: Pogaku $R$ (ed) Horizons in Bioprocess Engineering. Springer International Publishing, Cham, pp 73-90. https://doi.org/10.1007/978-3-030-29069-6_5

Budtova T, Navard P (2016) Cellulose in $\mathrm{NaOH}-$ water based solvents: a review Cellulose 23:5-55 https://doi.org/10.1007/s10570-015-0779-8

Carrasco C et al. (2010) SO2-catalyzed steam pretreatment and fermentation of enzymatically hydrolyzed sugarcane bagasse Enzyme and Microbial Technology 46:64-73 https://doi.org/10.1016/j.enzmictec.2009.10.016

Chen Y, Stipanovic AJ, Winter WT, Wilson DB, Kim Y-J (2007) Effect of digestion by pure cellulases on crystallinity and average chain length for bacterial and microcrystalline celluloses Cellulose 14:283-293 https://doi.org/10.1007/s10570-007-9115-2

Chinga-Carrasco G et al. (2019) Bagasse-A major agro-industrial residue as potential resource for nanocellulose inks for 3D printing of wound dressing devices Additive $\quad$ Manufacturing 28:267-274 https://doi.org/10.1016/j.addma.2019.05.014

Cotana F, Cavalaglio G, Petrozzi A, Coccia V (2015) Lignocellulosic biomass feeding in biogas pathway: state of the art and plant layouts Energy Procedia 81:1231-1237 https://doi.org/10.1016/j.egypro.2015.12.334

Deepa B, Chirayil CJ, Pothan LA, Thomas S (2019) Lignocellulose-based nanoparticles and nanocomposites: preparation, properties, and applications. In: Lignocellulose for Future Bioeconomy. Elsevier, pp 41-69. https://doi.org/10.1016/B978-0-12-816354-2.00004-9

Delgado-Aguilar M, González I, Tarrés Q, Alcalà M, Pèlach MÀ, Mutjé P (2015a) Approaching a low-cost production of cellulose nanofibers for papermaking applications Bioresources 10:5345-5355 https://doi.org/10.15376/biores.10.3.5345-5355

Delgado-Aguilar M, González I, Tarrés Q, Pèlach MÀ, Alcalà M, Mutjé P (2016) The key role of lignin in the production of low-cost lignocellulosic nanofibres for papermaking applications Industrial Crops and Products 86:295-300 https://doi.org/10.1016/j.indcrop.2016.04.010

Delgado-Aguilar M, Tarrés Q, Pèlach MAn, Mutjé P, Fullana-i-Palmer P (2015b) Are cellulose nanofibers a solution for a more circular economy of paper products? Environmental Science \& Technology 49:12206-12213 https://doi.org/10.1021/acs.est.5b02676

Diop CIK, Tajvidi M, Bilodeau MA, Bousfield DW, Hunt JF (2017) Isolation of lignocellulose nanofibrils (LCNF) and application as adhesive replacement in wood composites: example of fiberboard Cellulose 24:3037-3050 https://doi.org/10.1007/s10570-017-1320-z

Espinosa E, Domínguez-Robles J, Sánchez R, Tarrés Q, Rodríguez A (2017a) The effect of pre-treatment on the production of lignocellulosic nanofibers and their application as a reinforcing agent in paper Cellulose 24:2605-2618 https://doi.org/10.1007/s10570-017-1281-2

Espinosa E, Sánchez R, Otero R, Domínguez-Robles J, Rodríguez A (2017b) A comparative study of the suitability of different cereal straws for lignocellulose nanofibers isolation International Journal of Biological Macromolecules https://doi.org/10.1016/j.jjbiomac.2017.05.156 
Feng Y-H, Cheng T-Y, Yang W-G, Ma P-T, He H-Z, Yin X-C, Yu X-X (2018) Characteristics and environmentally friendly extraction of cellulose nanofibrils from sugarcane bagasse Industrial Crops and Products 111:285-291 https://doi.org/10.1016/j.indcrop.2017.10.041

García A, Gandini A, Labidi J, Belgacem N, Bras J (2016) Industrial and crop wastes: A new source for nanocellulose biorefinery Industrial Crops and Products 93:26-38 https://doi.org/10.1016/j.indcrop.2016.06.004

Ghaemi F, Abdullah LC, Ariffin H (2019) Lignocellulose structure and the effect on nanocellulose production. In: Lignocellulose for Future Bioeconomy. Elsevier, pp 17-30. https://doi.org/10.1016/B978-0-12-816354-2.00002-5

Gu L, Jiang B, Song J, Jin Y, Xiao H (2019) Effect of lignin on performance of lignocellulose nanofibrils for durable superhydrophobic surface Cellulose 26:933-944 https://doi.org/10.1007/s10570-018-2129-0

Han X et al. (2021) Use of endoglucanase and accessory enzymes to facilitate mechanical pulp nanofibrillation ACS Sustainable Chemistry \& Engineering 9:1406-1413 https://doi.org/10.1021/acssuschemeng.0c08588

Hendriks A, Zeeman G (2009) Pretreatments to enhance the digestibility of lignocellulosic biomass Bioresource Technology 100:10-18 https://doi.org/10.1016/j.biortech.2008.05.027

Hermans JJ, Hermans PH, Vermaas D, Weidinger A (1946) Quantitative evaluation of orientation in cellulose fibres from the X-ray fibre diagram Recueil des Travaux Chimiques des Pays-Bas 65:427-447 https://doi.org/10.1002/recl.19460650605

Herrera M, Thitiwutthisakul K, Yang X, Rujitanaroj P-o, Rojas R, Berglund L (2018) Preparation and evaluation of high-lignin content cellulose nanofibrils from eucalyptus pulp Cellulose 25:3121-3133 https://doi.org/10.1007/s10570018-1764-9

Hiloidhari $\mathrm{M}$ et al. (2020) Agroindustry wastes: biofuels and biomaterials feedstocks for sustainable rural development. In: Refining Biomass Residues for Sustainable Energy and Bioproducts. Elsevier, pp 357-388. https://doi.org/10.1016/B978-0-12-818996-2.00016-8

Hu Y, Wang B, Liu W, Wu R, Hou Q (2019) Effects of mechanical pretreatments on enzymatic hydrolysis of mixed lignocellulosic substrates for biorefineries BioResources 14:4639-4652

Huang J, Dufresne A, Lin N (2019) Nanocellulose: from fundamentals to advanced materials. John Wiley \& Sons,

Huggins ML (1942) The viscosity of dilute solutions of long-chain molecules. IV. Dependence on concentration Journal of the American Chemical Society 64:2716-2718 https://doi.org/10.1021/ja01263a056

Jiang Y, Liu X, Yang Q, Song X, Qin C, Wang S, Li K (2018) Effects of residual lignin on mechanical defibrillation process of cellulosic fiber for producing lignocellulose nanofibrils Cellulose 25:6479-6494 https://doi.org/10.1007/s10570-018-2042-6

Kamali M, Khodaparast Z (2015) Review on recent developments on pulp and paper mill wastewater treatment Ecotoxicology and Environmental Safety 114:326-342 https://doi.org/10.1016/j.ecoenv.2014.05.005

Kargarzadeh H, loelovich M, Ahmad I, Thomas S, Dufresne A (2017) Methods for Extraction of Nanocellulose from Various Sources. In: Handbook of Nanocellulose and Cellulose Nanocomposites. pp 1-49. https://doi.org/10.1002/9783527689972.ch1

Khalil HA, Davoudpour Y, Islam MN, Mustapha A, Sudesh K, Dungani R, Jawaid M (2014) Production and modification of nanofibrillated cellulose using various mechanical processes: a review Carbohydrate Polymers 99:649665 https://doi.org/10.1016/j.carbpol.2013.08.069 
Kraemer EO (1938) Molecular weights of celluloses and cellulose Derivates

loses and cellulose Derivates
Chemistry $30: 1200-1203$ https://doi.org/10.1021/ie50346a023

Kumagai A, Endo T, Adachi M (2019) Evaluation of cellulose nanofibers by using sedimentation method Japan Tappi Journal:461-469 https://doi.org/10.2524/jtappij.1901

Kumar A, Negi YS, Choudhary V, Bhardwaj NK (2014) Characterization of cellulose nanocrystals produced by acid-hydrolysis from sugarcane bagasse as agro-waste Journal of Materials Physics and Chemistry 2:1-8 http://dx.doi.org/10.1007/978-3-642-27758-0 1162-2

Lee $\mathrm{H}$, Hamid S, Zain S (2014) Conversion of lignocellulosic biomass to nanocellulose: structure and chemical process The Scientific World Journal 2014:1-20 https://doi.org/10.1155/2014/631013

Liu D, Chen X, Yue Y, Chen M, Wu Q (2011) Structure and rheology of nanocrystalline cellulose Carbohydrate Polymers 84:316-322 https://doi.org/10.1016/j.carbpol.2010.11.039

Lu X, Feng X, Li X, Zhao J (2018) The adsorption properties of endoglucanase to lignin and their impact on hydrolysis Bioresource Technology 267:110-116 https://doi.org/10.1016/j.biortech.2018.06.031

Mariano M, El Kissi N, Dufresne A (2014) Cellulose nanocrystals and related nanocomposites: review of some properties and challenges Journal of Polymer Science Part B: Polymer Physics 52:791-806 https://doi.org/10.1002/polb.23490

Martino DC, Colodette JL, Chandra R, Saddler J (2017) Steam explosion pretreatment used to remove hemicellulose to enhance the production of a eucalyptus organosolv dissolving pulp Wood Science and Technology 51:557-569 https://doi.org/10.1007/s00226-016-0889-y

Mathur R, Srivastava V (2019) Crop residue burning: effects on environment. In: Greenhouse Gas Emissions. Springer, pp 127-140. http://dx.doi.org/10.1007/978-981-13-3272-2_9

Metgen (2021) A new wave in bio-based materials. https://www.metgen.com/wpcontent/uploads/2020/10/MetGen-Company-Presentation.pdf. Accessed april, 20212021

Moraes Rocha GJ, Martin C, Soares IB, Maior AMS, Baudel HM, De Abreu CAM (2011) Dilute mixed-acid pretreatment of sugarcane bagasse for ethanol production Biomass and Bioenergy 35:663-670 https://doi.org/10.1016/j.biombioe.2010.10.018

Nan F, Nagarajan S, Chen Y, Liu P, Duan Y, Men Y, Zhang J (2017) Enhanced toughness and thermal stability of cellulose nanocrystal iridescent films by alkali treatment ACS Sustainable Chemistry \& Engineering 5:8951-8958 https://doi.org/10.1021/acssuschemeng.7b01749

Nguyen TC, Anne-Archard D, Fillaudeau L (2015) Rheology of lignocellulose suspensions and impact of hydrolysis: a review. In: Krull R, Bley $\mathrm{T}$ (eds) Filaments in Bioprocesses. Springer International Publishing, Cham, pp 325-357. https://doi.org/10.1007/10_2015_323

Pereira B, Arantes V (2020) Production of cellulose nanocrystals integrated into a biochemical sugar platform process via enzymatic hydrolysis at high solid loading Industrial Crops and Products 152:112377-112388 https://doi.org/10.1016/j.indcrop.2020.112377

Pereira Ramos L, Domingos Fontana J (2004) Enzymatic saccharification of cellulosic materials. In: Walker JM, Spencer JFT, Ragout de Spencer AL (eds) Environmental Microbiology: Methods and Protocols. Humana Press, Totowa, NJ, pp 219-233. https://doi.org/10.1385/1-59259-765-3:219

Pirich CL, Picheth GF, Machado JPE, Sakakibara CN, Martin AA, de Freitas RA, Sierakowski MR (2019) Influence of mechanical pretreatment to isolate 
cellulose nanocrystals by sulfuric acid hydrolysis International Journal of Biological Macromolecules https://doi.org/10.1016/j.ijbiomac.2019.02.166 130:622-626

Pitarelo AP, Fonseca CSd, Chiarello LM, Gírio FM, Ramos LP (2016) Ethanol production from sugarcane bagasse using phosphoric acid-catalyzed steam explosion Journal of the Brazilian Chemical Society 27:1889-1898 http://dx.doi.org/10.5935/0103-5053.20160075

Potulski DC, Viana LC, de Muniz G, de Andrade AS, Klock U (2016) Characterization of fibrillated cellulose nanofilms obtained at different consistencies Scientia Forestalis 44:361-372

Rocha GJM, Gonçalves AR, Oliveira BR, Olivares EG, Rossell CEV (2012) Steam explosion pretreatment reproduction and alkaline delignification reactions performed on a pilot scale with sugarcane bagasse for bioethanol production Industrial Crops and Products 35:274-279 https://doi.org/10.1016/j.indcrop.2011.07.010

Rojo E, Peresin MS, Sampson WW, Hoeger IC, Vartiainen J, Laine J, Rojas OJ (2015) Comprehensive elucidation of the effect of residual lignin on the physical, barrier, mechanical and surface properties of nanocellulose films Green Chemistry 17:1853-1866 https://doi.org/10.1039/C4GC02398F

Saelee K, Yingkamhaeng N, Nimchua T, Sukyai P (2016) An environmentally friendly xylanase-assisted pretreatment for cellulose nanofibrils isolation from sugarcane bagasse by high-pressure homogenization Industrial Crops and Products 82:149-160 https://doi.org/10.1016/j.indcrop.2015.11.064

Samaniuk JR, Wang J, Root TW, Scott CT, Klingenberg DJ (2011) Rheology of concentrated biomass Korea-Australia Rheology Journal 23:237-245 https://doi.org/10.1007/s13367-011-0029-z

Silva ASA, Inoue H, Endo T, Yano S, Bon EPS (2010) Milling pretreatment of sugarcane bagasse and straw for enzymatic hydrolysis and ethanol fermentation Bioresource Technology 101:7402-7409 https://doi.org/10.1016/j.biortech.2010.05.008

Silva CG, Kano FS, Rosa DS (2019) Lignocellulosic nanofiber from eucalyptus waste by a green process and their influence in bionanocomposites Waste and Biomass

Valorization:1-14 https://doi.org/10.1016/j.indcrop.2015.11.064

Simha R (1940) The influence of brownian movement on the viscosity of solutions The Journal of Physical Chemistry 44:25-34 https://doi.org/10.1021/j150397a004

Sucharitpong T, Lam NT, Sukyai P (2020) Production of nylon-6/cellulose nanocrystal composite films using solvent dissolution Sugar Tech 22:328$339 \mathrm{https}: / /$ doi.org/10.1007/s12355-019-00775-0

Sukyai $P$ et al. (2018) Effect of cellulose nanocrystals from sugarcane bagasse on whey protein isolate-based films Food Research International 107:528-535 https://doi.org/10.1016/j.foodres.2018.02.052

Szczerbowski D, Pitarelo AP, Zandoná Filho A, Ramos LP (2014) Sugarcane biomass for biorefineries: Comparative composition of carbohydrate and non-carbohydrate components of bagasse and straw Carbohydrate Polymers 114:95-101 https://doi.org/10.1016/j.carbpol.2014.07.052

Tarrés Q, Saguer E, Pèlach MA, Alcalà M, Delgado-Aguilar M, Mutjé P (2016) The feasibility of incorporating cellulose micro/nanofibers in papermaking processes: the relevance of enzymatic hydrolysis Cellulose 23:1433-1445 https://doi.org/10.1007/s10570-016-0889-y

Teo HL, Wahab RA (2020) Towards an eco-friendly deconstruction of agroindustrial biomass and preparation of renewable cellulose nanomaterials: 
A review International Journal of Biological Macromolecules https://doi.org/10.1016/j.ijbiomac.2020.08.076

Thompson G, Swain J, Kay M, Forster C (2001) The treatment of pulp and paper mill effluent: a review Bioresource Technology 77:275-286 https://doi.org/10.1016/S0960-8524(00)00060-2

Varanasi S, He R, Batchelor W (2013) Estimation of cellulose nanofibre aspect ratio from measurements of fibre suspension gel point Cellulose 20:1885$1896 \mathrm{https}: / /$ doi.org/10.1007/s10570-013-9972-9

Viana LC, Muñiz GIBd, Magalhães WLE, Andrade ASd, Nisgoski S, Potulski DC (2019) Filmes nanoestruturados produzidos a partir de polpa kraft branqueada de Pinus $s p$ Floresta e Ambiente 26:1-10 https://doi.org/10.1590/2179-8087.019115

Wu B, Wang S, Tang J, Lin N (2019) Nanocellulose in high-value applications for reported trial and commercial products. In: Advanced Functional Materials from Nanopolysaccharides. Springer, pp 389-409. http://dx.doi.org/10.1007/978-981-15-0913-1 11

Xie H, Du H, Yang X, Si C (2018) Recent strategies in preparation of cellulose nanocrystals and cellulose nanofibrils derived from raw cellulose materials International Journal of Polymer Science 2018:1-25 http://dx.doi.org/10.1155/2018/7923068

Zhang L, Wang T, Jiao S, Hao C, Mao Z Effect of steam-explosion on biodegradation of lignin in wheat straw. In: 2007 ASAE Annual Meeting, 2007. American Society of Agricultural and Biological Engineers, $p 1$. https://doi.org/10.1016/j.biortech.2008.03.028

Zhou Y, Saito T, Bergström L, Isogai A (2018) Acid-free preparation of cellulose nanocrystals by TEMPO oxidation and subsequent cavitation Biomacromolecules https://doi.org/10.1021/acs.biomac.7b01730 


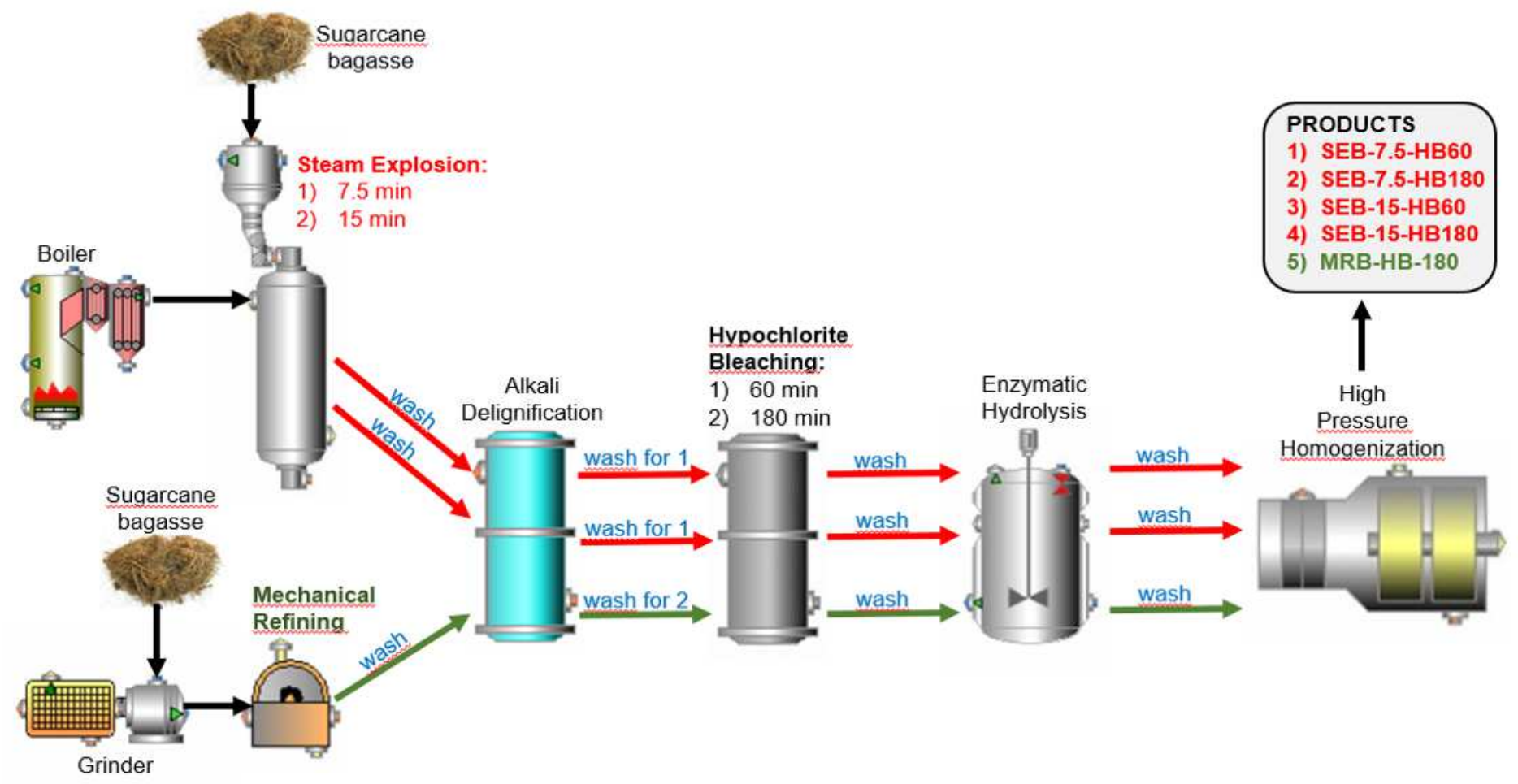

Figure 1

Flow diagram of the global reactions to obtain nanofibers of cellulose 


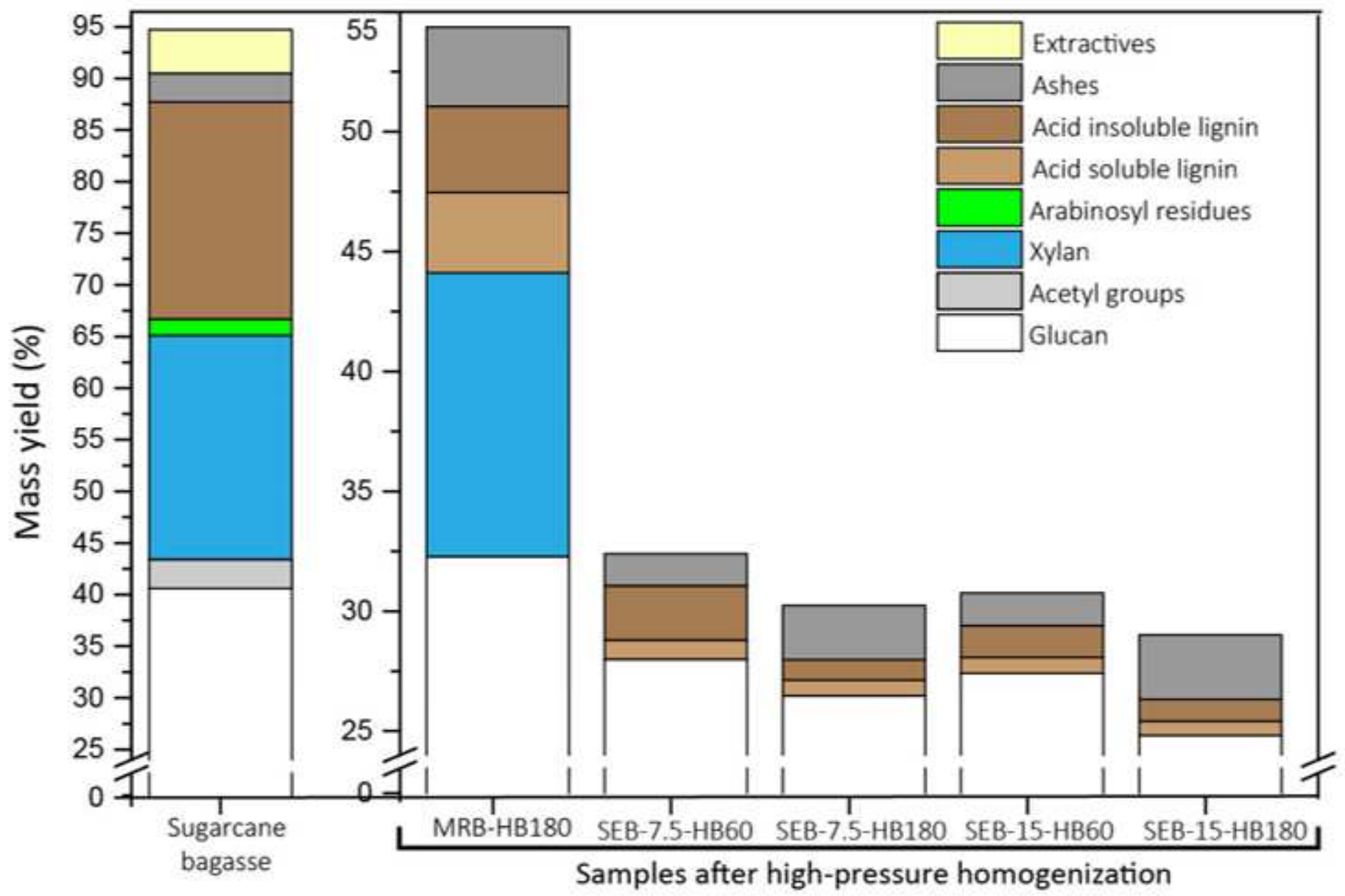

Figure 2

Chemical composition of sugarcane bagasse compared to lignocellulose nanomaterials that were obtained after mechanical refining or steam explosion $\left(7.5\right.$ and 15 min at $\left.195^{\circ} \mathrm{C}\right)$, followed by alkali washing, hypochlorite bleaching (60 and $180 \mathrm{~min}$ ), enzymatic hydrolysis, and high-pressure homogenization. 

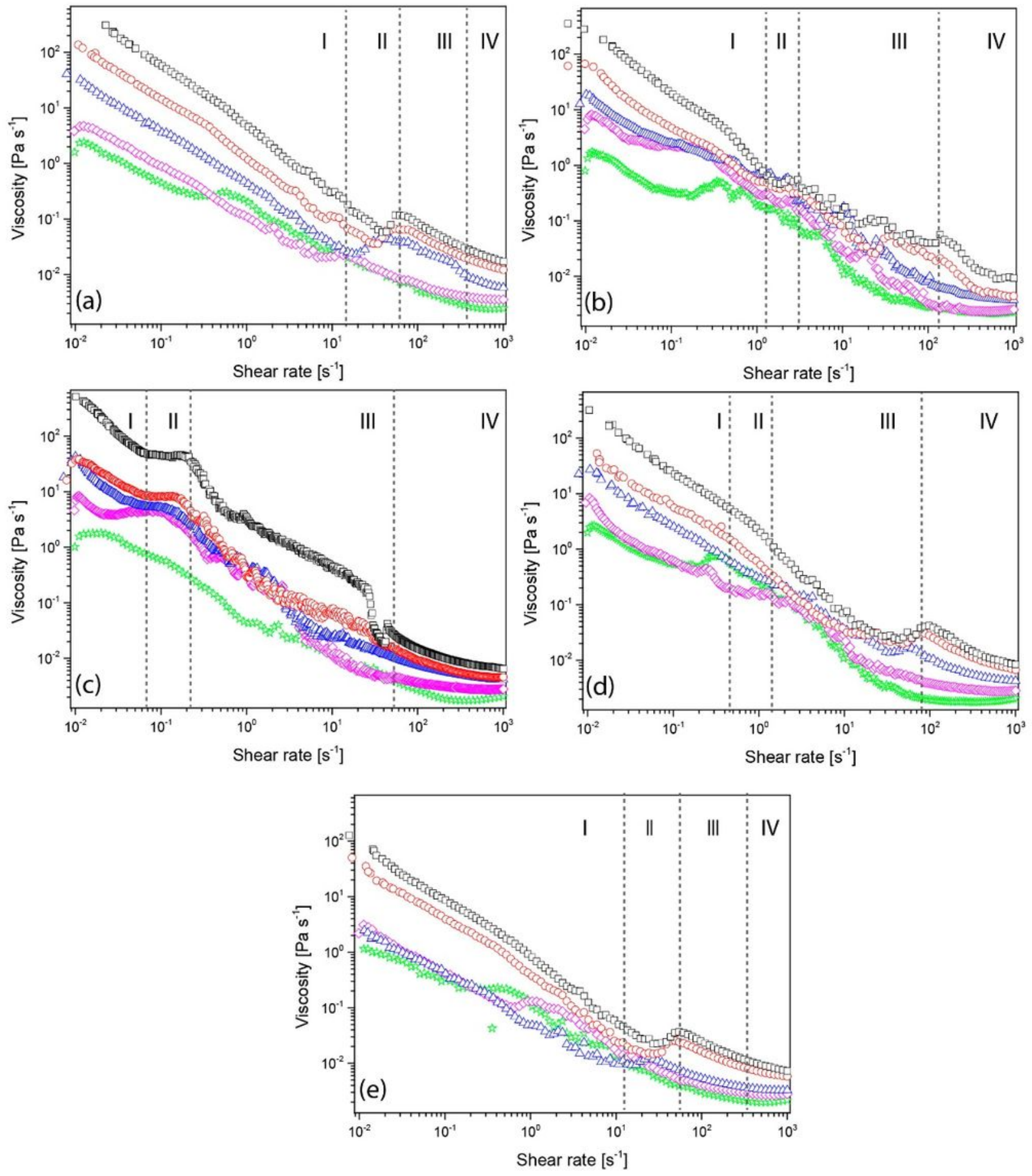

\section{Figure 3}

Steady-state viscosity vs. shear rate of (a) MRB-HB180, (b) SEB-7.5-HB60, (c) SEB-7.5-HB180, (d) SEB-15HB60 and (e) SEB-15-HB180 suspensions with concentrations of $1.0 \mathrm{mg} \mathrm{mL}-1$ (black squares), $2.5 \mathrm{mg}$ $\mathrm{mL}-1$ (red circles), $5 \mathrm{mg} \mathrm{mL}-1$ (blue triangles) and $10 \mathrm{mg} \mathrm{mL}-1$ (olive stars) at $25^{\circ} \mathrm{C}$. At low concentrations and low shear rates, viscosity could not be measured precisely due to limitations in the rheometer sensitivity. 

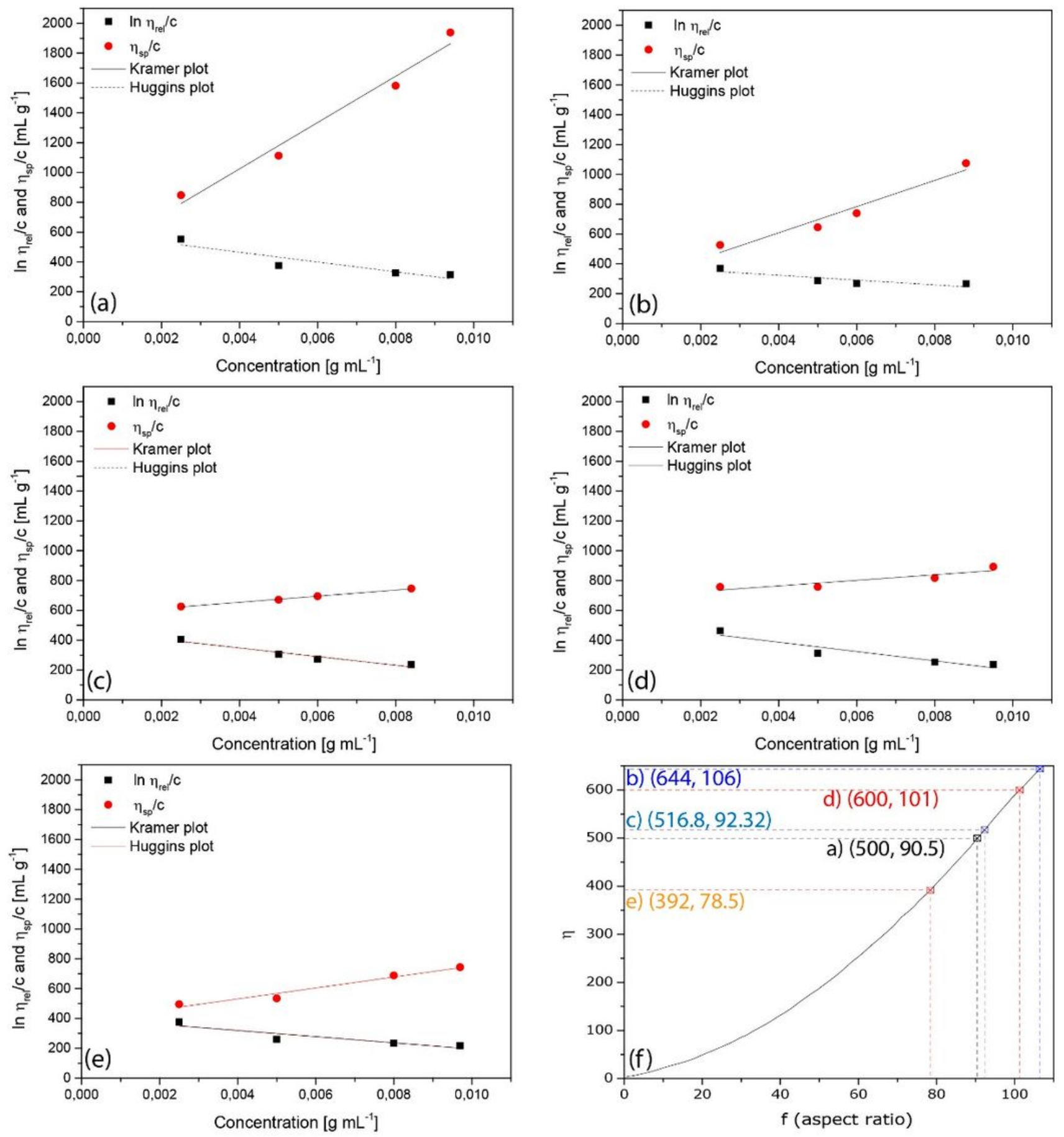

Figure 4

Values of In $\eta \mathrm{rel} / \mathrm{c}$ and $\eta \mathrm{sp} / \mathrm{c}$ and Kraemer and Huggins' plots for ultra-homogenized fibers suspensions: (a) MRB-HB180, (b) SEB-7.5-HB60, (c) SEB-7.5-HB180, (d) SEB-15-HB60 and (e) SEB-15-HB180 at a shear rate of $230 \mathrm{~s}-1$ at $25^{\circ} \mathrm{C}$ and (d) Simha's plot used to estimate the aspect ratio (f) of ultra-homogenized fibers. 

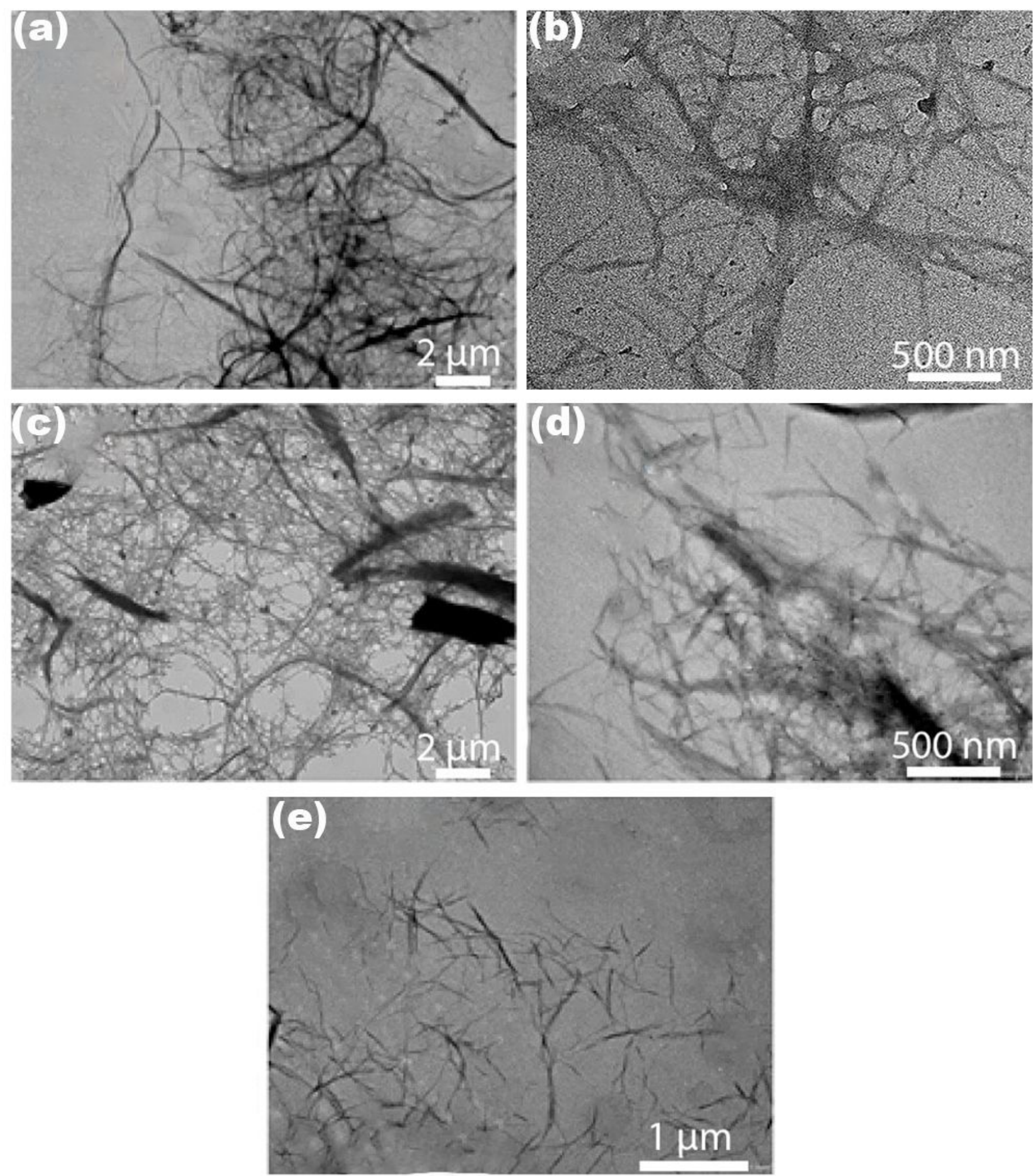

Figure 5

TEM micrographs of (a) MRB-HB180, (b) SEB-7.5-HB60, (c) SEB-7.5-HB180, (d) SEB-15-HB60 and (e) SEB15-HB180. 


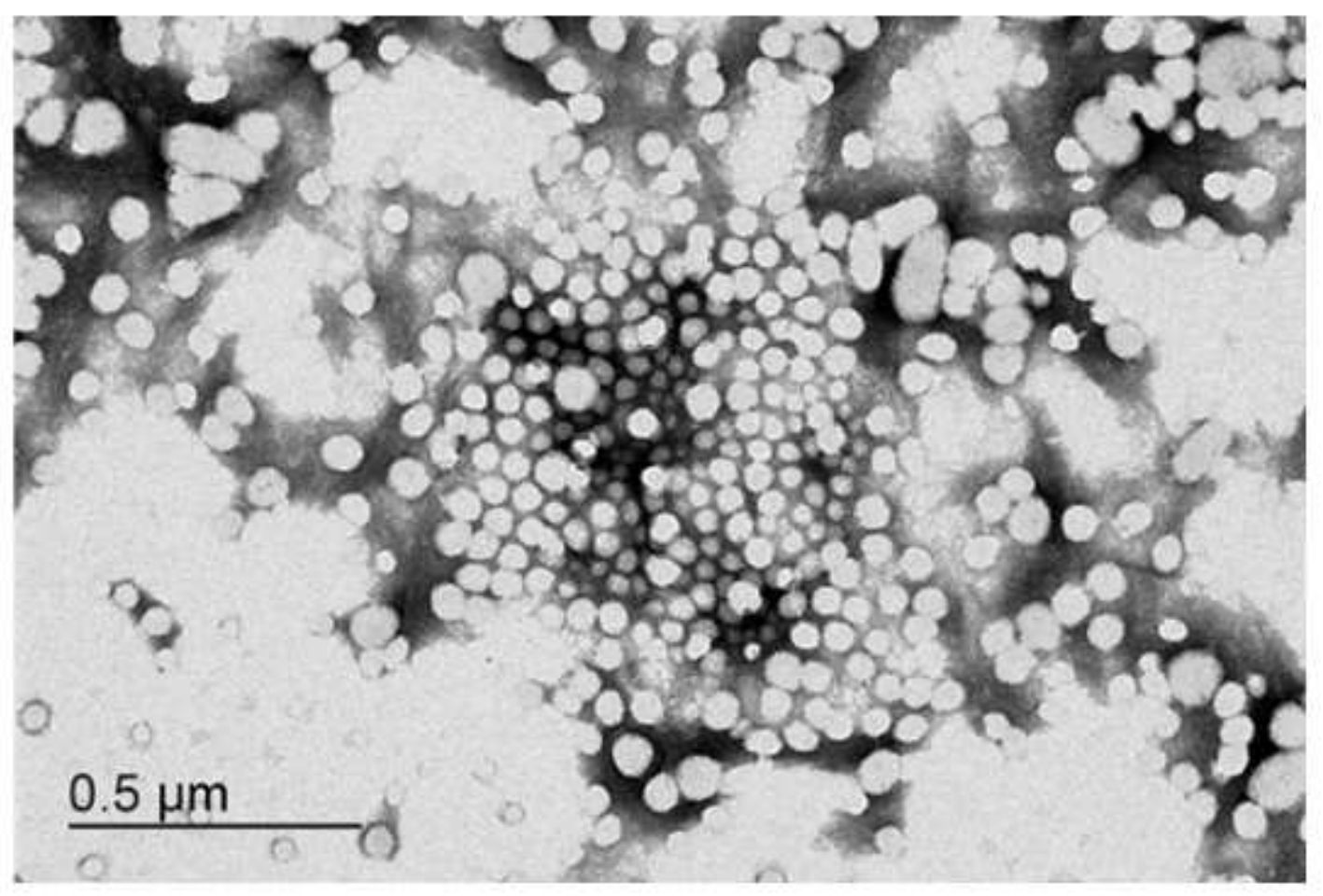

Figure 6

TEM micrograph of SEB-7.5-HB60 exhibiting agglomerated spherical nanoparticles. Visualization was improved by contrast using uranyl acetate.

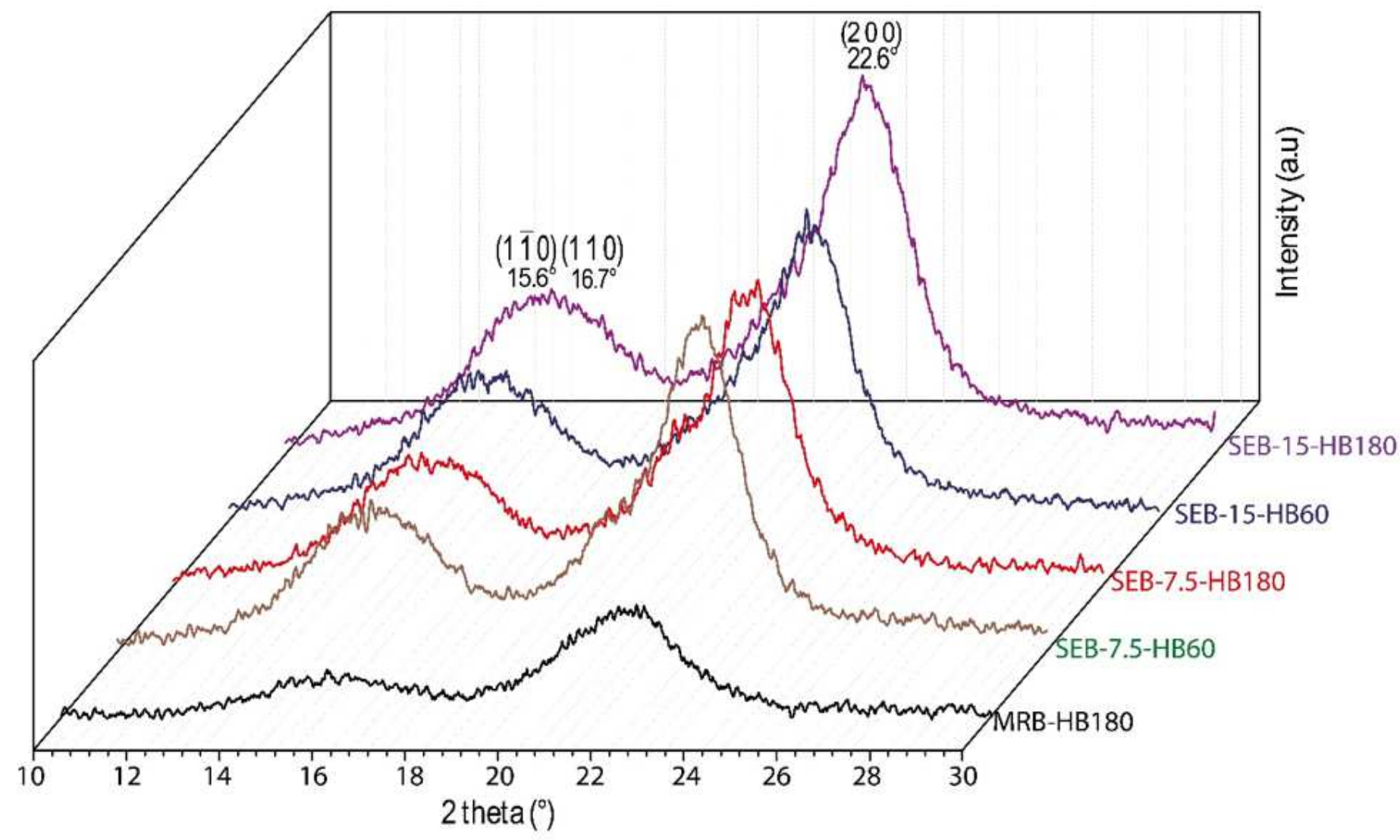


Figure 7

X-ray patterns of high-pressure homogenized samples

\section{Supplementary Files}

This is a list of supplementary files associated with this preprint. Click to download.

- graphicalabstract.png 